Renata Valeri de Freitas

\title{
Análise Temporal da Antena Espiral Equiangular Filamentar
}

Tese apresentada à Escola Politécnica da Universidade de São Paulo para obtenção do título de Doutora em Ciências

Área de Concentração:

Engenharia de Sistemas Eletrônicos

Orientador: Prof. Livre-Docente

Luiz Cezar Trintinalia

São Paulo 
Este exemplar foi revisado e corrigido em relação à versão original, sob responsabilidade única do autor e com a anuência de seu orientador.

São Paulo, de de

Assinatura do autor:

Assinatura do orientador:

\section{Catalogação-na-publicação}

Freitas, Renata Valeri de

Análise Temporal da Antena Espiral Equiangular Filamentar / R. V.

Freitas -- versão corr. -- São Paulo, 2017.

$74 \mathrm{p}$.

Tese (Doutorado) - Escola Politécnica da Universidade de São Paulo. Departamento de Engenharia de Sistemas Eletrônicos.

1.antenas 2.eletromagnetismo 3.transiente I.Universidade de São Paulo. Escola Politécnica. Departamento de Engenharia de Sistemas Eletrônicos II.t. 
Renata Valeri de Freitas

\section{Análise Temporal da Antena Espiral Equiangular Filamentar}

Tese apresentada à Escola Politécnica da Universidade de São Paulo para obtenção do título de Doutora em Ciências

São Paulo 


\section{Agradecimentos}

Várias pessoas e instituições tiveram participação relevante na minha vida professional e neste trabalho. Por isso, gostaria de deixar registrado meus agradecimentos.

À Fundação de Amparo à Pesquisa do Estado de São Paulo - FAPESP pelo financiamento de parte desse trabalho.

Ao Professor Phillip M.S. Burt pela sua dedicação e auxílio.

Ao Professor Silvio E. Barbin pelo trabalho desenvolvido em conjunto.

À Professora Amanda de Paula pela constante ajuda e dicas.

Ao Professor Coelho pelo entusiasmo, coaching e ajuda desde meu projeto de formatura.

Ao Professor Antônio R. Panicali especialmente pelo incentivo ao pensamento fora da caixa e dicas bibliográficas.

Ao Engenheiro, empresário e radioamador Percival G. Netto pelo exemplo de dedicação ao desenvolvimento da tecnologia nacional.

Ao orientador, Professor Luiz C. Trintinalia por acreditar no trabalho e participar dos momentos difíceis durante as longas discussões nos últimos anos. Enfim, tornar esse trabalho possível. 
"Knowledge is subtractive, not additive - what we subtract (reduction by what does not work, what not to do), not what we add (what to do)"

(Nassim Nicholas Taleb)

"Life's not about how hard of a hit you can give... it's about how many you can take, and still keep moving forward."

(Sylvester Stallone, Rocky Balboa) 


\section{Resumo}

Por conta da liberação de uma nova faixa de espectro as aplicações que utilizam transmissão em banda ultralarga se expandiram. Por conta disso, várias formas de transmissão pulsada ganharam destaque. Contudo, o projeto e estudo de antenas até então era majoritariamente feito em banda estreita e regime permanente senoidal. Além disso, para transmissão pulsada, a resposta impulsiva da antena passa a ser mais necessária do que sua resposta em banda estreita. Por isso, o objetivo desse estudo foi explorar o que ocorre com pulsos estreitos se propagando em uma antena de forma a se obter uma aproximação da resposta impulsiva de antenas. Mais especificamente, foi obtido um modelo analítico que explicita a relação entre a geometria e o funcionamento da antena. Através do estudo da espiral equiangular foi possível encontrar o decaimento do pulso de corrente ao longo da linha como também o campo radiado de forma quantitativa. Tal resultado, assim como os procedimentos para sua obtenção, poderá ser utilizado para outras antenas filamentares. 


\begin{abstract}
The applications for Ultra Wide Band have grown since the new regulation allowed the use of a new large frequency band. Since then, systems for pulsed transmission entered the spotlight. However, the antenna's project and study were in big part done in narrowband and sinusoidal steady-state. Besides, the impulse response is of much more interest for these systems than the frequency response. For this reason, the main goal of this work is to explore how current pulses propagate on the antenna to obtain an approximate impulse response. Moreover, an analytical model that unveils the relation between the antenna geometry and its current decay is presented. Through the study of the equiangular spiral it is possible to find the pulse decay as a function of the line length and the radiated field in a quantitative fashion. This result as well as the methods used to obtain it can be used for other antennas.
\end{abstract}




\section{Sumário}

1 Introdução 2

2 Contexto 5

3 Visão Geral $\quad 7$

4 Metodologia e ferramentas desenvolvidas para a obtenção dos $\begin{array}{lr}\text { resultados simulados } & 9\end{array}$

4.1 Projeto da antena e divisão em segmentos . . . . . . . . . . . . . . 10

4.2 Arquivos de simulação e extração dos resultados . . . . . . . . . . . . 11

4.3 Obtenção da aproximação para a resposta impulsiva . . . . . . . . . . 21

5 Cálculo do campo radiado a partir do modelo de carga puntiforme acelerada $\quad \mathbf{2 6}$

5.1 Campos de um dipolo infinitesimal no domínio do tempo . . . . . . 26

5.2 Campos radiados por um dipolo infinitesimal a partir do modelo de radiação de uma carga acelerada . . . . . . . . . . . . . . . . 32

6 Estudo da antena espiral equiangular $\quad 35$

6.1 Equação da antena espiral equiangular . . . . . . . . . . . . 36

6.2 Equação da antena espiral simulada . . . . . . . . . . . . . . . 37

6.3 Aceleração centrípeta em coordenadas esféricas . . . . . . . . . . . 41

6.4 Expressão para corrente em função do raio de curvatura . . . . . . . . 44

6.5 Modelo simplificado . . . . . . . . . . . . . . . 47

6.6 Estimativa do campo em valor absoluto e com o decaimento da corrente 48

$\begin{array}{lll}7 & \text { Conclusão } & 52\end{array}$

8 Anexos $\quad 54$

$\begin{array}{ll}\text { Referências Bibliográficas } & 63\end{array}$ 


\section{Capítulo 1}

\section{Introdução}

As aplicações comerciais da transmissão pulsada foram alavancadas após a alocação de uma grande faixa de espectro para uso civil feita por diversos países como Estados Unidos, Japão, China e os países da União Européia [1, 7, 33]. Tal fato gerou um terreno aberto para o desenvolvimento de novos sistemas completos em uma diversidade de áreas. $\mathrm{O}$ uso desse espectro em banda larga motivou o desenvolvimento de geradores de pulsos, antenas, sistemas de modulação, radares e sistemas de medidas assim como novas formas de se avaliar e comparar sistemas pulsados.

As antenas dividem-se em dois grupos em função do método de ocupação do espectro escolhido. Para esquemas de modulação que dividem o espectro em regiões menores, como por exemplo o OFDM-UWB, o projeto, a análise e a caracterização das antenas podem ser feitos de maneira bastante próxima ao de antenas de banda estreita que já é amplamente conhecido [39], utilizando, por exemplo, uma rede de antenas com elementos adaptados para cada subdivisão do espectro. Nos esquemas de modulação que utilizam pulsos gaussianos ou outro tipo de forma de onda pulsada, para os quais a antena deverá apresentar preferencialmente características constantes por todo o espectro, os métodos de projeto convencionais não são adequados [15]. Esse fato representa um desafio para o projeto de antenas e gera a necessidade de uma compreensão mais profunda dos fenômenos de radiação para excitações transientes $[14,27,28]$.

Levando em conta a relevância atual de sistemas UWB e que, apesar de várias antenas já terem sido propostas para aplicação em banda ultralarga, poucas vezes o princípio de funcionamento dessas antenas foi explorado [37]. O objetivo deste trabalho é, portanto, obter um modelo analítico que explicite a relação entre a geometria e o funcionamento da antena. Para tanto, utilizou-se um pulso estreito o suficiente para ocupar somente um pequeno comprimento $d l$ da antena em cada 
instante de tempo, permitindo a visualização do que ocorre com o pulso em cada ponto da antena separadamente. Essa abordagem se mostrou essencial para a obtenção de resultados relevantes.

O estudo da propagação de pulsos ao longo da estrutura de antenas é capaz de fornecer muitas informações sobre o processo de radiação. À medida que o domínio sobre o processo de radiação aumenta, é possível projetar antenas e sistemas capazes de cumprir suas funções eficientemente. Com o objetivo de esclarecer e aperfeiçoar o entendimento sobre o processo de radiação de antenas, neste trabalho de Doutorado, que se iniciou no Mestrado, foram desenvolvidas inicialmente ferramentas capazes de simular estruturas filamentares grandes, com uma duração de pulso bem menor do que o tempo levado pela luz para percorrer a antena.

O primeiro tipo de análise, feita a partir dos resultados da simulação, foi obter o tempo de chegada das perturbações no ponto de observação e relacionar as regiões da antena às perturbações do campo elétrico. Esse estudo foi feito para dipolos de diversos comprimentos, com geradores de corrente e de tensão. Observou-se que as fontes de radiação em um dipolo são suas extremidades e o próprio gerador. Os resultados desse estudo foram publicados em [38] artigo contemplado como melhor artigo de estudante do congresso IMOC.

O mesmo estudo foi feito para uma antena espiral equiangular, onde foi possível identificar a combinação dos efeitos de curvatura e de tempo de chegada formando picos no sinal recebido [11]. Conforme esse tipo de análise se desenvolveu, foi possível mostrar que as expressões da física utilizadas para obter a radiação de cargas em movimento $[22,17]$ resultam em campos radiados equivalentes ao obtidos por simulação da antena utilizando o método dos momentos quando normalizados. Ou seja, é possível prever o campo radiado por uma antena pulsada analiticamente, sem a necessidade de se recorrer a métodos numéricos.

Devido ao resultado promissor desse estudo, decidiu-se continuá-lo em um trabalho de Doutorado. As ferramentas de simulação foram aprimoradas, resultando em uma formulação teórica mais robusta e consequentemente resultados mais confiáveis. Com isso, foi possível obter com precisão o formato do pulso radiado também nas direções de maior interesse da antena. Esse resultado foi publicado no Transactions on Antennas and Propagation [10].

O estudo progrediu em seguida para o cálculo do campo radiado em valor absoluto, sem a necessidade de normalização, como será mostrado mais adiante. Notou-se que, apesar de o campo obtido aproximar satisfatoriamente o campo radiado, para se obter uma precisão maior seria necessário conhecer o decaimento da amplitude do pulso ao longo da antena. Contudo, encontrar o decaimento do 
pulso de corrente na antena não é tarefa simples.

Primeiramente, foi necessário incluir nas ferramentas as rotinas para extração e interpolação dos valores de corrente. Em seguida, diferentes geometrias foram simuladas e suas correntes foram estudadas, com o objetivo de observar o comportamento da amplitude do pulso de corrente em diferentes estruturas e levantar hipóteses sobre a relação entre a distribuição de corrente e os campos em torno da antena. Uma das antenas estudadas foi o dipolo dobrado, que resultou em um artigo na Conferência Européia de Antenas e Propagação [9].

Após observar a corrente na antena, era necessário descrevê-la matematicamente. Várias abordagens foram adotadas incluindo: balanço de energia, conservação do momento em ondas eletromagnéticas, estudo via modelos de linha de transmissão com perdas e parâmetros variáveis. Finalmente, um modelo bem enxuto e simples foi o que produziu um melhor resultado. Nesse modelo a energia perdida da onda que se propaga na linha é igualada à energia perdida por radiação devido a uma carga puntiforme que percorre a trajetoria delimitada pela antena. Ao resolver esta equação diferencial foi possível encontrar o tipo de função que aproxima o decaimento de corrente. Essa função depende somente dos parâmetros que descrevem a geometria da antena. Além disso, o método utilizado poderá ser testado futuramente em qualquer outra estrutura filamentar a partir somente das expressões de suas coordenadas em função do comprimento.

A apresentação será feita na seguinte sequência: no capítulo 2 o contexto atual da transmissão pulsada, com exemplos de aplicações e limitações, é apresentado com o objetivo de exemplificar as aplicações tecnológicas que se beneficiariam de ferramentas mais adaptadas ao projeto de antenas pulsadas, além de apresentar parte do contexto tecnológico atual. Em seguida no Capítulo 3, são descritas as ferramentas de simulação desenvolvidas que foram utilizadas no trabalho e sua fundamentação teórica. No Capítulo 4 é explorado como o modelo de carga acelerada corresponde aos modelos de elemento infinitesimal de corrente utilizados em regime permanente senoidal. No capítulo 5 é apresentada a aproximação para o decaimento do pulso de corrente e é feita a incorporação desse modelo no cálculo do campo radiado. Por fim, no capítulo 6, são apresentadas a conclusão e as possibilidades de desenvolvimento futuro do trabalho. 


\section{Capítulo 2}

\section{Contexto}

O uso de antenas para transmissão de pulsos em sistemas de comunicação, equipamentos médicos, identificação de propriedades de materiais e imagens se tornou onipresente. Após a liberação de faixas de frequência em diversos países, crescem o número de sistemas utilizando pulsos de banda larga. Redes de antenas são usadas para radar pulsado UWB (Ultra Wide Band) em ambientes reflexivos, como tanques metálicos contendo líquidos [30]. Sistemas completos UWB que utilizam pulsos de 400ps de duração, foram desenvolvidos para Radares de impulso de micropotência (Micropower Impulse Radar), ou seja, radares de baixo custo com uma sensibilidade grande a distâncias bem curtas [25]. Sensores implantáveis para medição de sinais biológicos utilizando IR-UWB (Impulse Radio UWB), utilizando modulação por posição de pulso (Pulse Position Modulation), também ganharam atenção devido ao seu consumo menor de energia e menor necessidade de processamento no front-end [26]. Antenas UWB de alta fidelidade feitas completamente de tecidos também foram propostas para uso em WBANs (Wireless Body Area Networks) com requisitos específicos de redução de lóbulos traseiros para reduzir a exposição do usuário à radiação [40]. Sistemas de varredura para investigação geofísica extraterrestre utilizando antenas Vivaldi também foram construídos [34], com operação na banda de 1 a 5 GHz.

A transmissão UWB também é utilizada para sistemas de alta potência, inclusive para aplicações militares. Em [20], uma antena diretiva capaz de radiar pulsos de até $75 \mathrm{kV}$ e 0, 83ns de duração na faixa entre 0,207 a 2,33 GHz é apresentada. Contudo, nada garante que os equipamentos eletrônicos existentes não sofram interferência de sistemas de transmissão UWB. De fato, sistemas UWB podem causar o mau funcionamento de marca-passos [3]. Por isso, também é necessário a adaptação dos padrões de ensaios de compatibilidade eletromagnética, já que eles são feitos em regime permanente senoidal e supondo interferências radiadas de banda estreita. Em 
[32] um gerador de $125 \mathrm{kV}$, com pulsos de $5 \mathrm{~ns}$ de duração e capacidade de regulagem para formatação do pulso, foi apresentado. Esse gerador possui um alcance de $10 \mathrm{a}$ 20 metros, sendo propício para ensaios de susceptibilidade radiada.

Isso levou também à necessidade de evoluir a tecnologia de proteção contra pulsos UWB para equipamentos. Em [12, 13], são apresentadas duas estruturas em circuito impresso de baixo custo para a proteção contra pulsos UWB. Formas de se medir o diagrama de radiação de antenas UWB fora de uma câmara anecoica também foram propostas [29] e são válidas entre $300 M H z$ e $3 G H z$.

Ou seja, o desenvolvimento dessas aplicações causarão adaptações em toda a cadeia produtiva de equipamentos eletrônicos. Assim como as aplicações expandiram, as pesquisas teóricas também o fizeram.

Estudos sobre a aderência dos limites de campo distante em regime permanente senoidal e seu significado para a transmissão pulsada foram estudados [21]. Isso é importante pois, antenas de banda larga muitas vezes são usadas para comunicações e radares de curta distância, não sendo compatíveis com as aproximações de campo distante realizadas até então em regime permanente senoidal.

A estimativa do alcance de radares e sua precisão também necessitaram de refinamento devido à grande largura de banda. Os efeitos determinísticos e aleatórios que afetam a estimativa do alcance de radares UWB foram discutidos em [35]. Os efeitos de miniatuarização de antenas, como perda de fidelidade do pulso transmitido e efeitos na impedância de entrada também foram estudados [24].

Em todas as áreas citadas anteriormente são usadas antenas que variam em tamanho e em formato. Portanto, explorar o funcionamento das antenas é um esforço necessário que pode trazer benefícios ao desenvolvimento de diversas aplicações. 


\section{Capítulo 3}

\section{Visão Geral}

Independentemente do tipo de antena, o campo radiado está sempre intimamente ligado à capacidade da antena de acelerar cargas. Para se ter controle da condição inicial da antena e evitar variações devidas à impedância de entrada, foi utilizado o gerador de corrente. De fato, são cargas em movimento que causam ondas eletromagnéticas [19]. Por isso, se faz necessário conhecer a corrente e não a tensão na antena.

Dessa forma, é a presença de cargas aceleradas que gera campo distante. Tal relação está explícita nos campos de aceleração descritos em [36], onde a expressão para o campo distante é uma função direta da aceleração. Portanto, para se entender como uma antena radia basta entender como a antena causa a aceleração de cargas.

Essa aceleração pode ser decomposta em duas componentes vetoriais, uma na direção do movimento e uma perpendicular a este. De maneira que ou a carga é acelerada ou desacelerada na mesma direção da velocidade, o que é causado por reflexões, ou ela é submetida à aceleração centrípeta causada por curvas na estrutura. Uma antena interessante de estudar por suas propriedades invariantes em frequência é a antena espiral. Esse tipo de antena é usado frequentemente, inclusive em redes de antenas $[18,8,16]$.

A antena espiral equiangular é uma antena conhecida pelas suas características de banda larga [6] e por proporcionar uma curvatura variável. A aceleração causada por essa espiral foi calculada e ela decai com o inverso do comprimento. Uma vez obtido o campo radiado para um pulso de carga, tão estreito quanto se queira, tem-se uma aproximação da resposta impulsiva da antena. Nessa resposta impulsiva o campo radiado é a saída desejada e a entrada é o pulso de corrente. Ou seja, uma antena e seu campo radiado podem ser estudados a partir de então como um sistema linear. Assim, de posse da resposta impulsiva, através da convolução é possível conhecer a saída para qualquer pulso e os parâmetros de distorção e desempenho podem ser 
calculados. Essa abordagem foi apresentada na primeira parte do estudo [11]. O capítulo seguinte descreve como esse estudo foi executado. 


\section{Capítulo 4}

\section{Metodologia e ferramentas desenvolvidas para a obtenção dos resultados simulados}

Ao analisar dipolos de comprimentos variados percebeu-se que, para entender o fenômeno de oscilação ( ringing) e sua relação com a geometria, é necessário estudar antenas de comprimento grande com relação ao comprimento de onda, para ser possível dividir o fenômeno em partes menores a fim de melhor interpretá-lo.

Para se obter a corrente e o campo radiado no domínio do tempo pode-se utilizar um programa que trabalha diretamente no domínio do tempo, ou um programa que encontra a resposta da antena para diversas frequências e depois transformar os resultados para o domínio do tempo [31]. Os programas de cálculo no domínio do tempo como HFSS e CST utilizam elementos finitos, o que dificulta sua utilização para o caso de estruturas grandes com relação ao comprimento de onda e o cálculo de campos a uma distância grande da antena. Por isso, optou-se por utilizar um software que é mais eficiente para esse tipo de problema, o software 4NEC2, que utiliza o método dos momentos e faz a simulação para sinais de entrada senoidais. Com isso é possível obter a reposta em frequência e em seguida usar a Transformada de Fourier Discreta para obter o resultado no domínio do tempo. Outra vantagem é que o software é baseado em um software de domínio público o NEC2, com a adição de uma interface de utilização mais prática e algumas opções extras de edição da geometria.

Durante o desenvolvimento do trabalho, scripts foram desenvolvidos no Matlab para automatizar a extração, processamento e plotagem dos resultados no domínio do tempo. As seções seguintes apresentam o detalhamento da forma final de obtenção e processamento desses resultados. 


\subsection{Projeto da antena e divisão em segmentos}

As antenas estudadas foram escolhidas de forma a apresentarem uma complexidade crescente. Para as antenas mais complexas foi necessário desenvolver macros no Excel para se obter segmentos com tamanho controlados e iguais e gerar o arquivo texto necessário para o 4NEC2.

Para que os resultados da simulação sejam representativos da realidade é necessário modelar a estrutura com uma discretização que seja coerente com o método numérico aplicado pelo simulador. O NEC2 utiliza o método dos momentos e tem como diretrizes gerais para a estrutura [4]:

- O tamanho do segmento $s$ deve ser menor que um décimo do comprimento de onda $s_{\max }<\lambda / 10$

- O tamanho do segmento $s$ deve ser maior que um milésimo do comprimento de onda $s_{\min }>\lambda / 1000$;

- O tamanho do raio a deve ser menor que um décimo do tamanho do segmento $a<s / 10 \Rightarrow a<\lambda / 100$;

Para a menor frequência $10 \mathrm{MHz}$, temos $s_{\max }=\frac{3.10^{8}}{10.10^{6}} \frac{1}{10}=3 \mathrm{~m}$ e $s_{\min }=\frac{3.10^{8}}{10.10^{6}} \frac{1}{1000}=$ $0,03 \mathrm{~m}$. Já para a maior frequência, temos $s_{\max }=\frac{3.10^{8}}{25 \cdot 10^{9}} \frac{1}{10}=1,2 \mathrm{~mm}$. Isso mostra que a discretização espacial da antena não poderá ser a mesma em toda a faixa de frequências utilizada. Já o raio, necessariamente, deverá ser o mesmo para todas as frequências. O raio será ditado pelo menor comprimento de onda $a=\frac{\lambda_{\min }}{100}=$ $\frac{c / 25.10^{9}}{100}=0,11992 \mathrm{~mm}$. O raio utilizado foi $a=0,1 \mathrm{~mm}$.

Cada arquivo de simulação contém os dados de entrada: coordenadas de início e fim de cada segmento, número de divisões do segmento, o raio do fio, a condutividade do material, o tipo de fonte de alimentação, as frequências para a qual os resultados devem ser calculados, a distância e os ângulos $\theta$ e $\phi$ para os quais o campo elétrico e magnético devem ser calculados. A fonte utilizada foi uma fonte de corrente dada pelo cartão $E X 6$, ela é criada pelo programa 4 NEC através de uma fonte de tensão equivalente.

Como as simulações foram realizadas em uma banda grande de frequências, o tamanho do segmento foi sendo reduzido conforme as regras de acurácia do programa de simulação exigem. Cada vez que o tamanho do segmento necessita ser reduzido é necessário gerar um novo arquivo de simulação. A separação dos arquivos de entrada também é importante para o posterior processamento dos arquivos de saída. Os arquivos de saída tendem a ser muito grandes se houverem muitos segmentos, dificultando o tratamento computacional. 
Os arquivos de saída contêm os resultados da simulação separados para cada frequência. Para cada uma delas são apresentados os segmentos, suas posições e seu comprimento, juntamente com o valor do fasor da parte imaginária e da parte real da corrente. Também é obtida uma tabela com todos os valores de $\theta$ e $\phi$ para os quais os campos foram calculados, juntamente com os valores de módulo e fase dos fasores $E_{\theta}$ e $E_{\phi}$. Outra tabela também fornece os valores de Ganho para todos os ângulos calculados. Um resumo pode ser visto na Figura 4.1

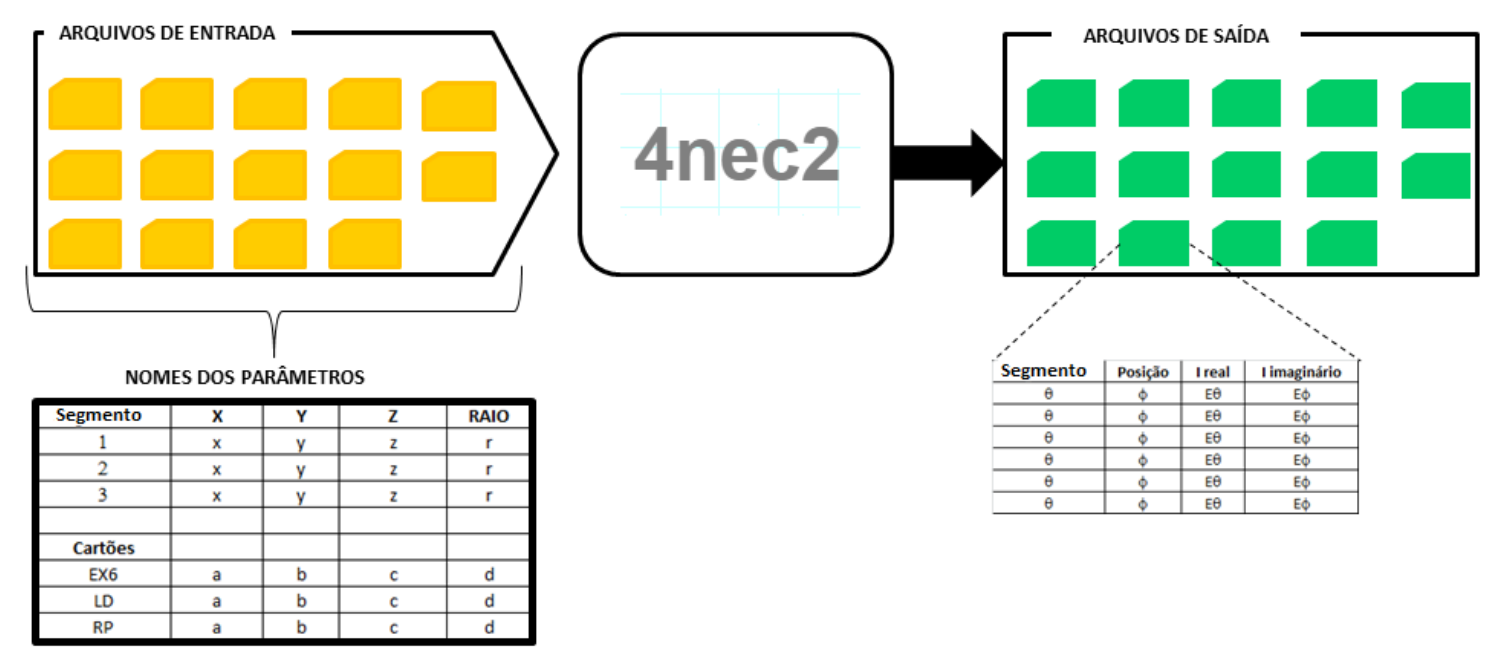

Figura 4.1: Parâmetros dos Arquivos de Entrada e Saída

\subsection{Arquivos de simulação e extração dos resultados}

Para simular a antena em todas as frequências, respeitando a discretização espacial necessária, é preciso gerar pelo menos 14 arquivos de entrada diferentes onde são especificadas as frequências para cada arquivo, as posições de cada segmento da antena, a distância e ângulo para os quais se deseja calcular o campo elétrico, o posicionamento e tipo de fonte a ser utilizado, a condutividade do fio e seu raio.

Esses arquivos de simulação podem então ser inseridos no 4NEC utilizando o recurso de processamento em batch. O resultado da simulação é fornecido pelo programa em um arquivo .out que possui formato texto. Nesse arquivo estão os dados da simulação e, para cada frequência da varredura, temos: a corrente em cada segmento com a parte real e imaginária, o campo radiado em cada direção escolhida para uma distância determinada, o valor da impedância de entrada, a potência total, a potência de perdas e potência radiada. 
Como existem pelo menos 14 arquivos de saída, cada um com resultados para duzentas frequências, foi necessário desenvolver um script no MATLAB para automaticamente abrir todos esses arquivos, encontrar para cada frequência os dados de interesse e colocá-los em variáveis que estejam em um formato indexado para serem usadas posteriormente para processamento. Para a corrente, por exemplo, esse script cria um vetor bidimensional onde temos o valor da corrente em função da posição e da frequência. A Figura 4.2 representa a matriz gerada por um único arquivo de simulação.

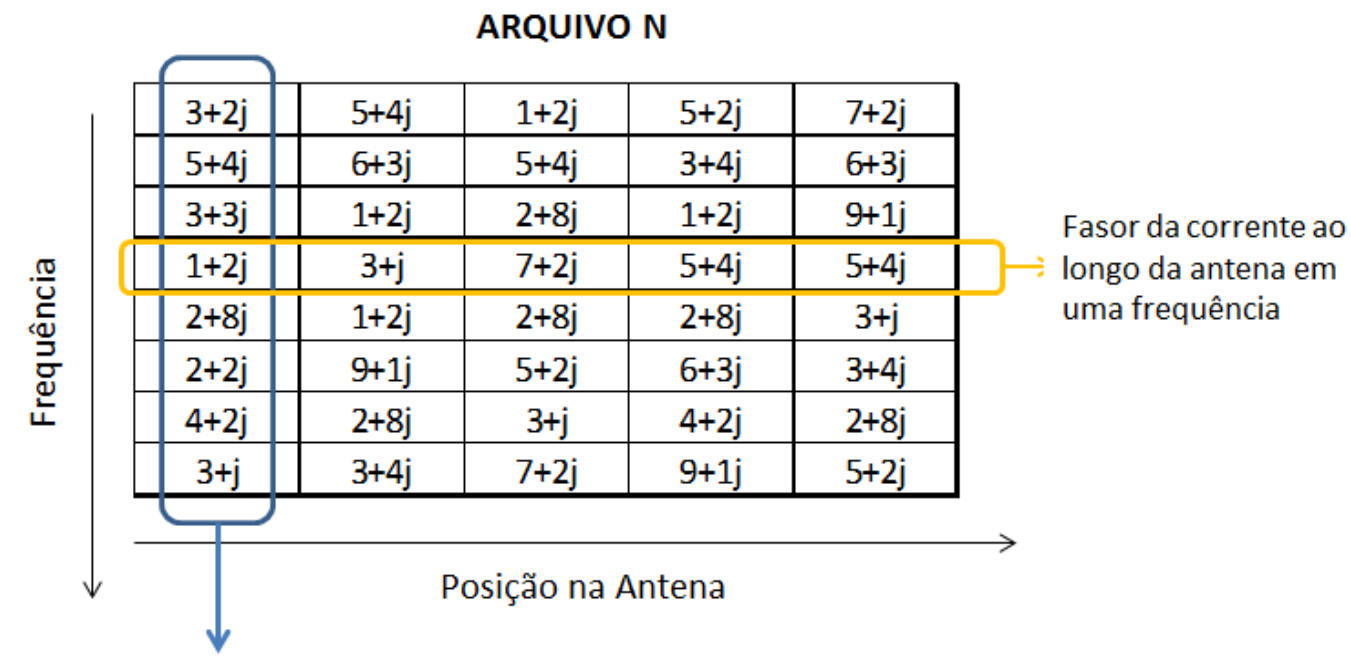

Resposta em Frequência do Fasor da corrente em uma mesma posição

Figura 4.2: Matriz extraída de um arquivo de saída do programa

A Figura 4.3 mostra o fasor da corrente ao longo da antena para uma frequência fixa. Nesse caso temos a corrente ao longo do tempo em uma determinada frequência

A Figura 4.4 mostra em uma posição fixa da antena a parte real e imaginária da corrente. Isso é equivalente a plotar uma linha da matriz anterior. Como esperado, em regime permanente senoidal, à medida que a frequência varia, as posições de máximo e mínimo também variam, por isso vemos que para algumas frequências a corrente será próxima de zero. 

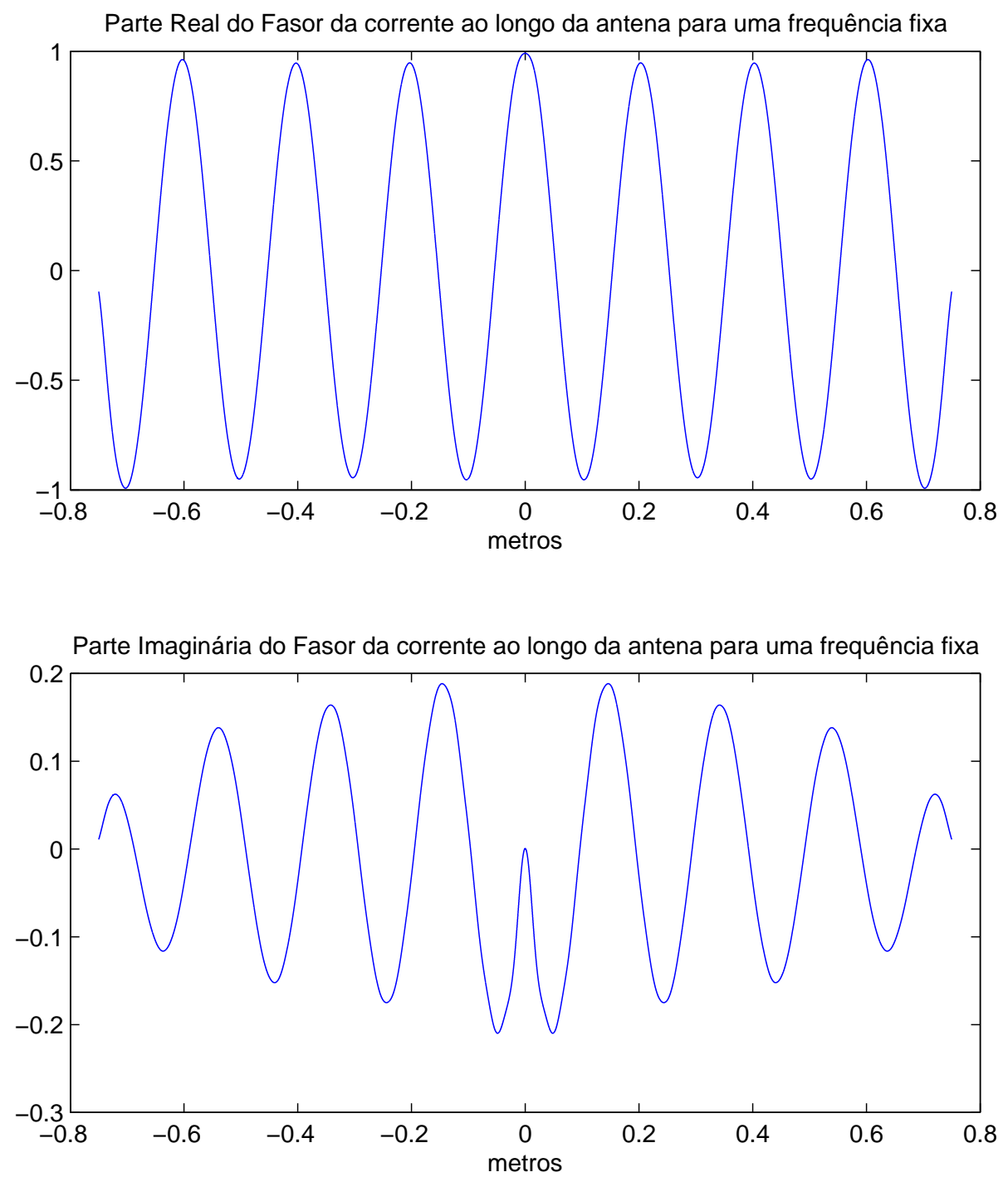

Figura 4.3: Fasor da Corrente ao longo da linha para uma frequência fixa 

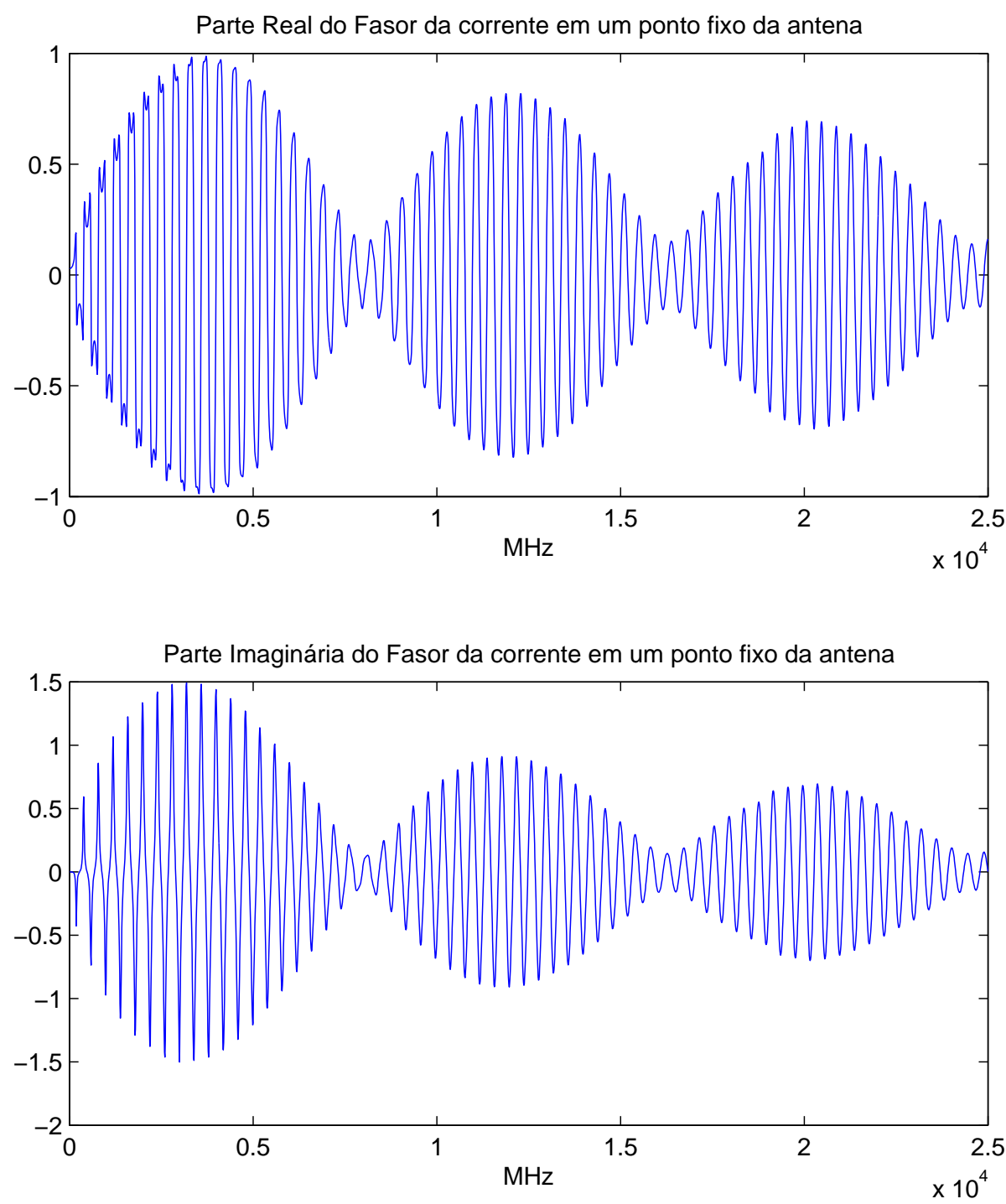

Figura 4.4: Fasor da corrente para um ponto da antena em função da frequência

As matrizes e os gráficos das figuras 4.1, 4.2, 4.3 e 4.4 ilustram os dados brutos iniciais disponíveis para se prosseguir com a análise da antena. Como esses dados estão no domínio da frequência, para visualizá-los no tempo é necessário realizar algumas operações.

A primeira providência é criar uma mesma base para as divisões do comprimento da antena. O passo de discretização espacial varia em função da frequência, sendo diferente para cada arquivo devido às restrições do tamanho do segmento que pode ser utilizado no 4NEC. Por isso, para cada arquivo de entrada criado, o passo diminui para levar em conta a diminuição do comprimento de onda. Assim, os resultados obtidos de corrente não são referentes ao mesmo ponto no espaço. 
Por isso, foi necessário interpolar os valores de corrente para que estes estivessem disponíveis em todas as frequências em uma mesma posição. Na Figura 4.5 temos uma representação desse procedimento:
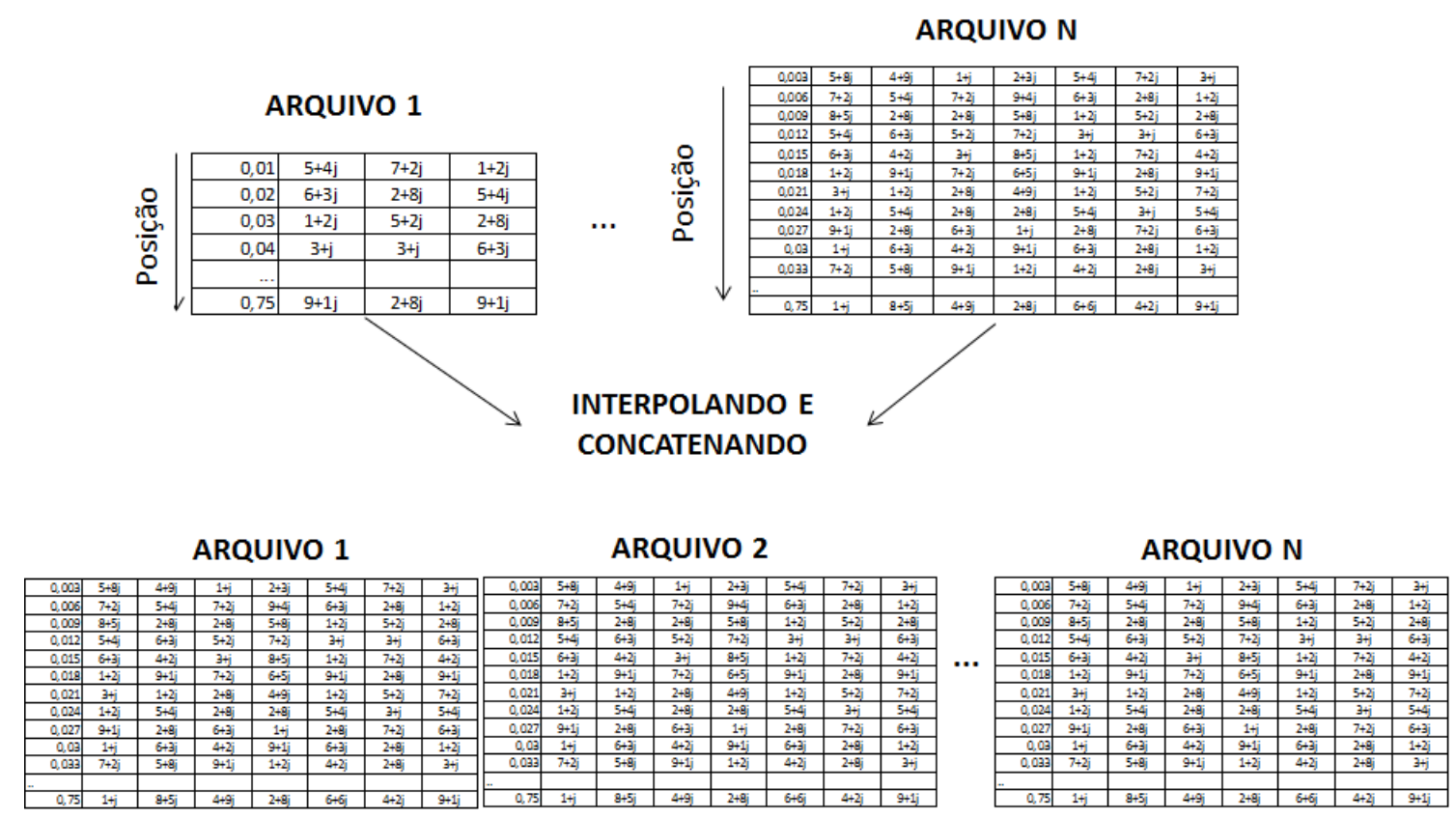

Figura 4.5: Interpolação e concatenamento dos dados

A rotina de interpolação desenvolvida inicialmente escolhe os segmentos pertencentes a um mesmo fio, ou seja, encontra no arquivo de saída gerado pelo 4NEC todos os segmentos pertencentes a um mesmo fio e suas respectivas posições, e usa a função de interpolação do Matlab, unindo os pontos com uma reta. Porém, conforme a evolução do trabalho e do nível de detalhe necessário para se observar a distribuição da corrente nas antenas, foi necessário refinar a interpolação. A interpolação final usada foi feita no MATLAB através de uma convolução com uma função sinc amostrada em um maior número de pontos, isso é equivalente a uma interpolação ideal com banda limitada. A Figura 4.6 mostra uma comparação das duas interpolações. 

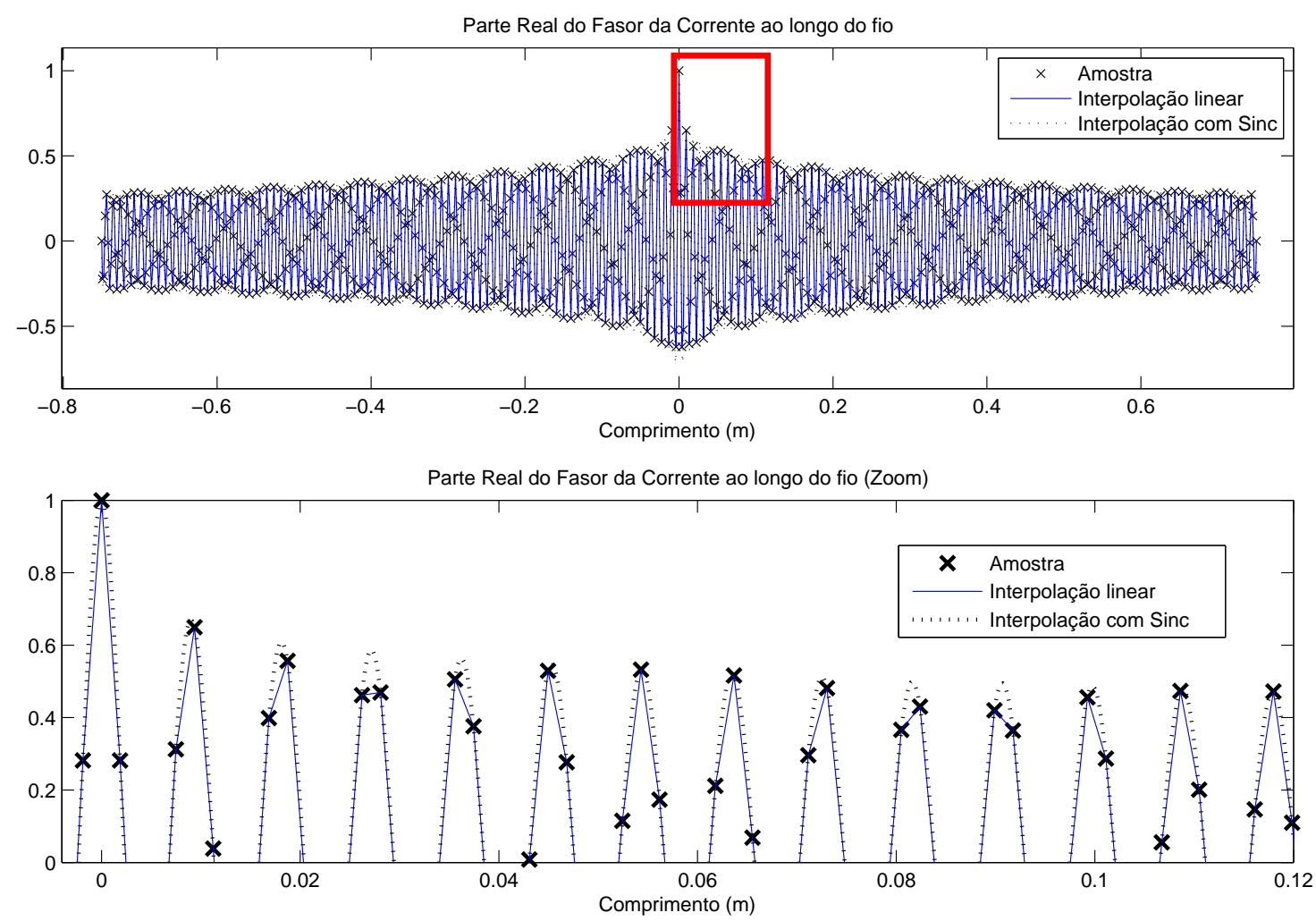

Figura 4.6: Comparação das formas de interpolação da corrente ao longo do comprimento da antena

Esse procedimento foi realizado para cada frequência de todos os arquivos. A largura da função sinc utilizada para a reconstrução é variável e foi calculada para cada caso, pois o passo de discretização também é variável.

Com a matriz original interpolada na sua parte real e imaginária é possível calcular a Transformada Discreta de Fourier Inversa. Procedimentos similares foram utilizados para encontrar o campo Elétrico e Magnético.

A IFFT foi realizada na matriz final com todos os dados já concatenados, obtendo uma nova matriz de dados com a mesma estrutura da anterior porém, com as linhas da matriz indexando as posições na antena e as colunas da matriz indexando os instantes de tempo, como mostra a Figura 4.7. 


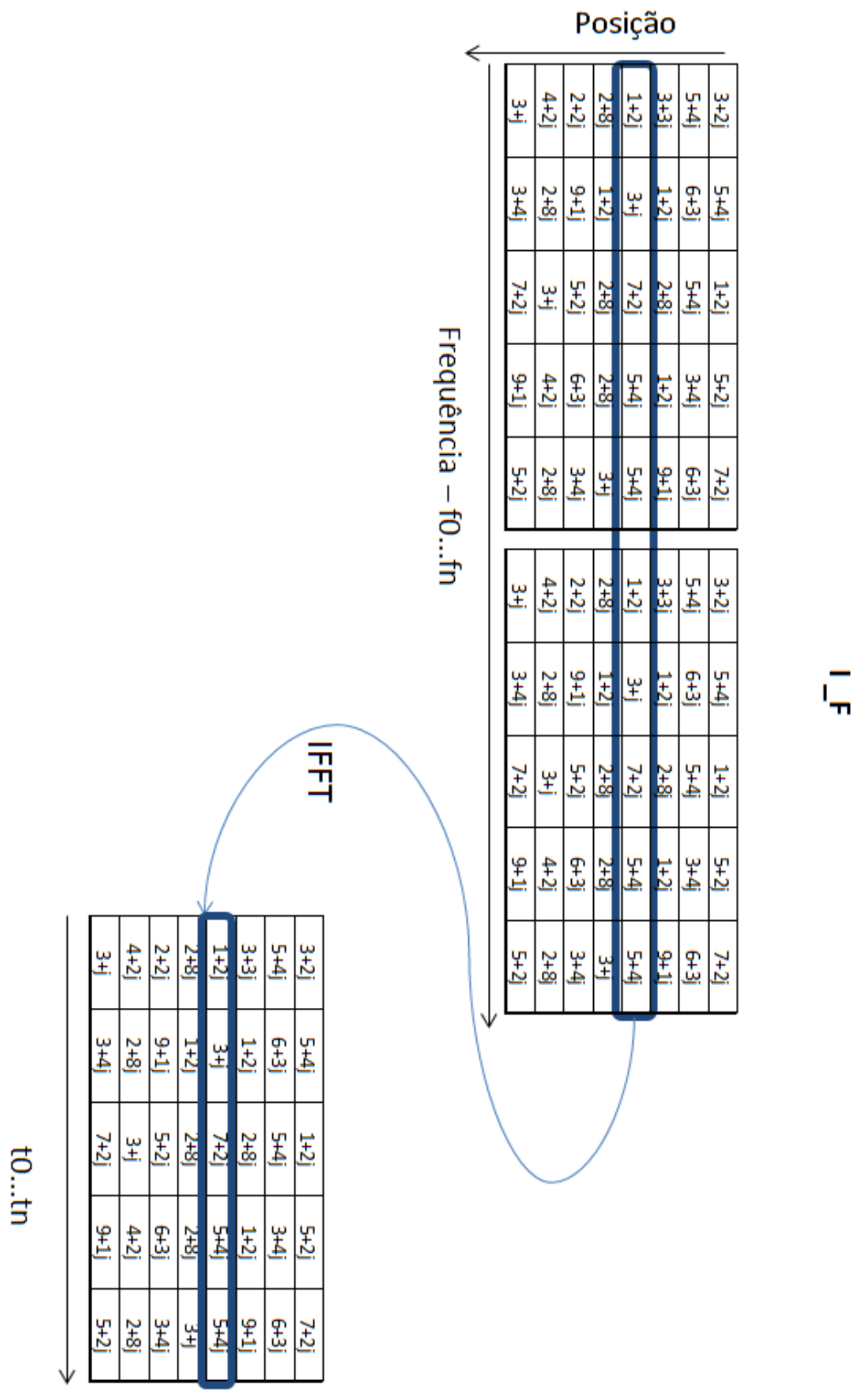

Figura 4.7: IFFT da matriz no domínio das frequências gerando a matriz no domínio do tempo 
Na Figura 4.8 tem-se a corrente em um ponto fixo da antena. Os pulsos observados são: o pulso inicial gerado pela fonte, um pulso de menor amplitude, devido à reflexão na extremidade da antena e por fim um pulso que foi refletido pelo gerador novamente. O passo de amostragem em frequência, que é responsável pela duração disponível no tempo, foi suficiente para visualizar toda a duração do fenomeno até a completa atenuação do pulso. Para assegurar que não haverá rebatimento espectral (aliasing) no domínio do tempo é necessário que o inverso do passo em frequência seja maior que a duração do sinal no domínio do tempo: $1 / \triangle f>T$. Como o passo em frequência utilizado foi de $\triangle f=10 M H z$, a duração do sinal deverá ser $T<0,1 \mu s$. O passo necessário e suficiente foi encontrado empiricamente, fazendo a simulação com um passo menor e depois aumentando quando possível. A Figura 4.8 mostra que realmente o passo utilizado foi suficiente para evitar o aliasing no tempo. Os detalhes sobre a conversão dos dados da frequência para o tempo serão esclarecidos na próxima seção. 

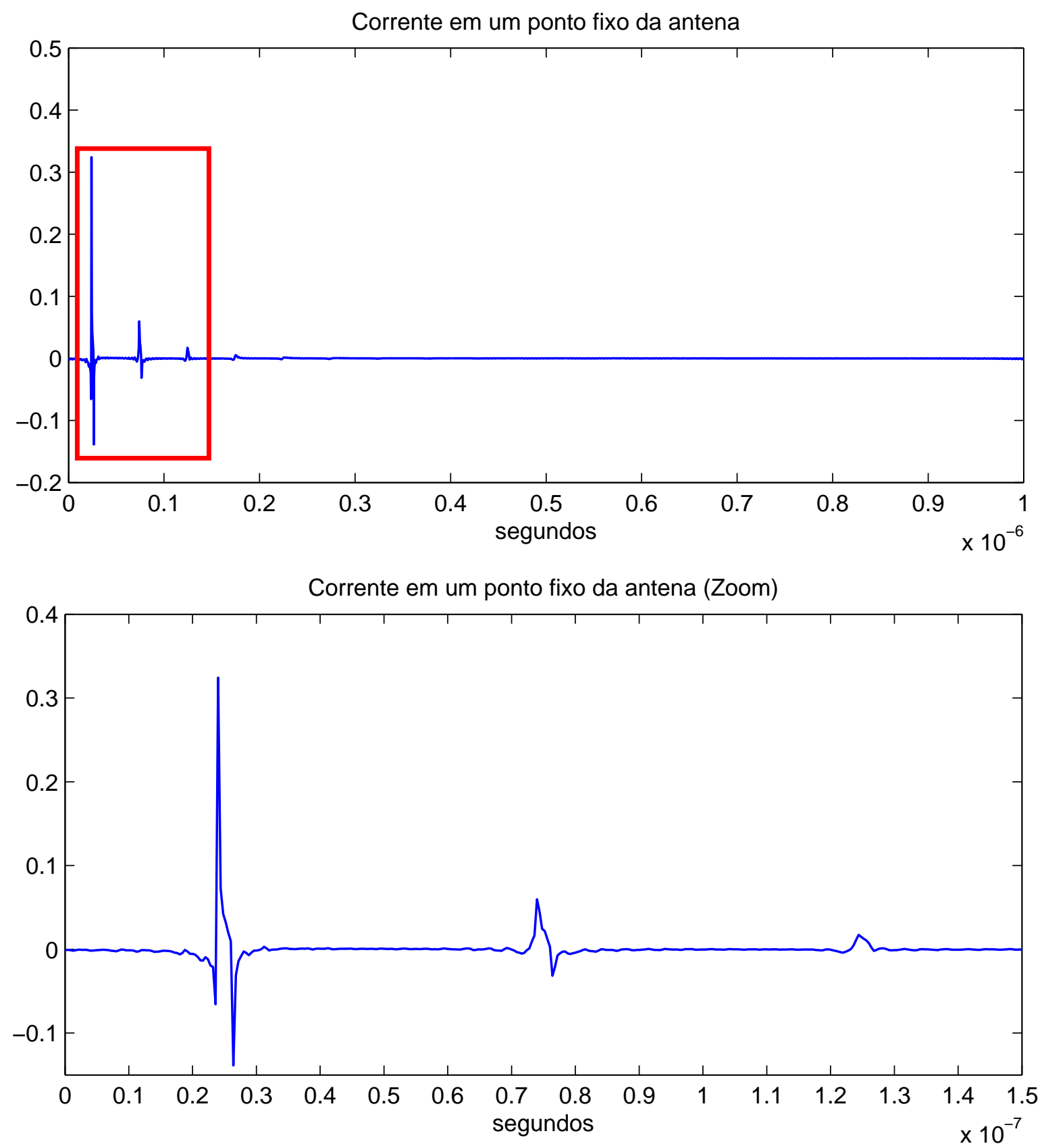

Figura 4.8: Corrente ao longo do tempo em um ponto fixo da antena

Na Figura 4.9 vemos o pulso em um instante fixo no tempo. Conforme o tempo passa, esse pulso se desloca em direção à extremidade. Nesse caso, o formato de sinc aparece porque o passo $\Delta l / c$ é menor que o passo no domínio do tempo $1 / f_{\max }$. Se utilizarmos um espaçamento idêntico ao usado no tempo esse efeito desaparece, como mostra a Figura 4.10. 

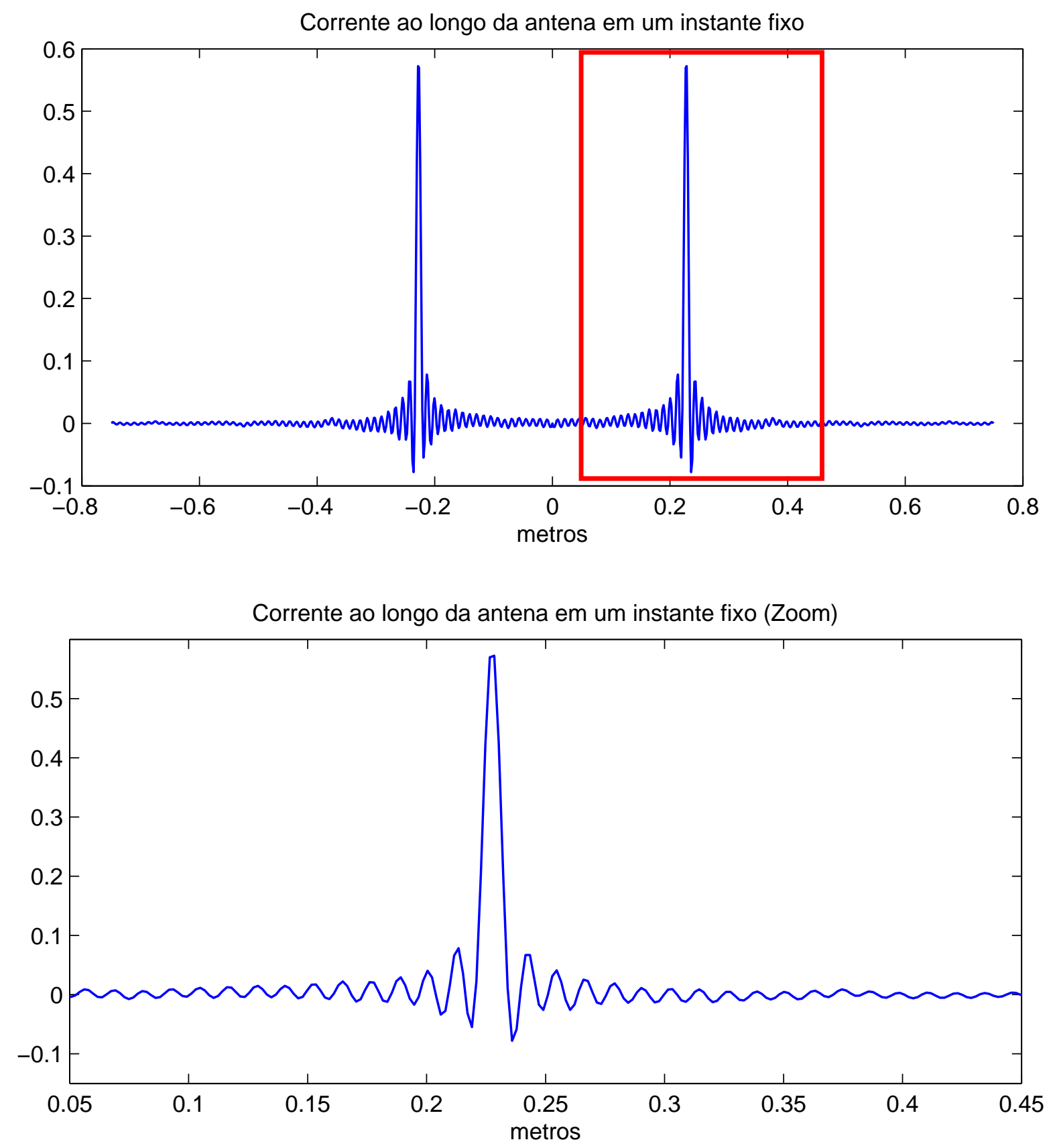

Figura 4.9: Corrente ao longo da antena em um instante fixo no tempo 


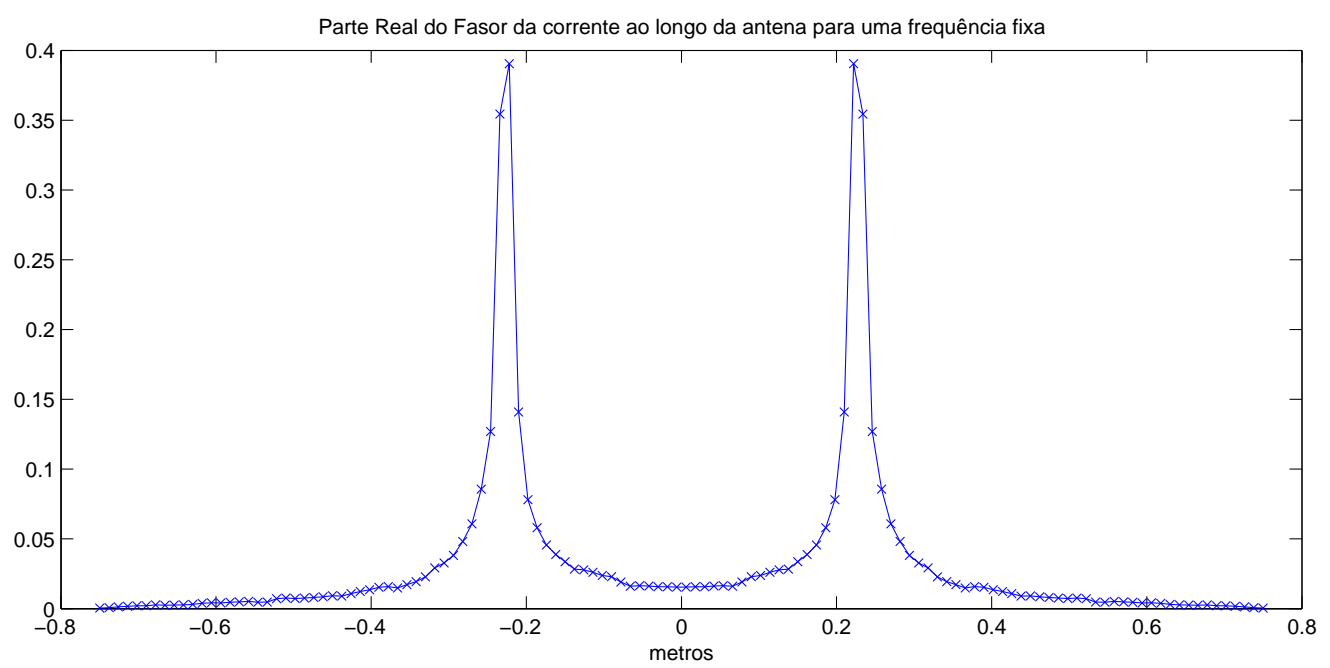

Figura 4.10: Corrente ao longo da antena com espaçamento espacial coerente com espaçamento temporal

\subsection{Obtenção da aproximação para a resposta impulsiva}

Os dados foram obtidos utilizando um passo em frequência $\triangle f$ e frequência máxima $f_{\text {max }}$. Baseados nessas amostras do espectro, deseja-se estimar a resposta impulsiva da antena. Contudo, é sabido que a obtenção da resposta impulsiva a partir de um espectro discreto apresenta distorções que não correspondem ao processo físico, e sim ao processo de estimação. Inicialmente, serão descritas as distorções esperadas devido à um processo de estimação dessa natureza.

A resposta impulsiva da antena pode ser obtida fazendo a Transformada de Fourier da sua resposta em frequência. Isso seria possível caso estivesse disponível a expressão analítica para essa resposta em frequência. Como essa expressão analítica não é conhecida, foi necessário fazer uma estimativa numérica.

A Figura 4.11 mostra, passo a passo, a relação entre o espectro real e o espectro utilizado. Com isso, é possível observar em paralelo quais alterações ocorreram na resposta impulsiva, tanto com relação à forma quanto à amplitude para posteriormente efetuar as correções possíveis.

O gráfico (a) da Figura 4.11 mostra uma representação do que seria a resposta em frequência real da antena em estudo. O gráfico (b) da Figura 4.11 mostra a resposta impulsiva real $h(t)$ que seria obtida através de uma Transformada de Fourier inversa desse espectro com uma hipotética amplitude $A$. Essa resposta é real e causal e portanto, seu espectro é do tipo apresentado na Figura (a). 
Contudo, o espectro não foi obtido para todas as frequências, mas foi truncado em $f_{\text {max }}$, o que é equivalente a multiplicar o espectro por uma janela retangular com limite em $f_{\max }$ Figura (e). A frequência máxima da janela utilizada foi escolhida de forma a ser maior do que os limites máximos das bandas alocadas para os sistemas UWB. Os resultados obtidos serão válidos para pulsos com conteúdo espectral até $f_{\max }=25 \mathrm{GHz}$, para pulsos com maior banda é necessário recalcular a resposta impulsiva.

Um truncamento do espectro é equivalente a multiplicar o espectro real por uma janela retangular. No domínio do tempo, essa janela retangular é equivalente a uma função sinc Figura (d) cujo lóbulo principal possui largura de $\frac{1}{f_{\max }}$, amplitude $2 f_{\max }$ e lóbulo lateral com amplitude $0,217 \cdot 2 f_{\max }$. A multiplicação no domínio da frequência causa uma convolução no tempo, o que corresponde a convoluir a reposta impulsiva da Figura (b) com uma função sinc da Figura (d). O resultado pode ser visto na Figura (f). A resposta no tempo sofrerá espalhamento e a largura total será a largura da resposta impulsiva mais a da função sinc e vazamento, com os lóbulos laterais gerando oscilações que na realidade não existem. A amplitude do pico será o resultado da seguinte convolução

$$
g_{\text {pico }}=2 f_{\max } \max \left(\int_{-\infty}^{\infty} h(\tau) w(t-\tau) d \tau\right)=2 f_{\max } \max \left(\int_{0}^{\infty} h(\tau) w(t-\tau) d \tau\right)
$$

Onde $w(t)$ é a representação de uma função sinc unitária no domínio do tempo. Supondo que $h(\tau)$ pode ser limitada entre 0 e $t_{1}$, temos

$$
g_{\text {pico }}=2 f_{\text {max }} \max \left(\int_{0}^{t_{1}} h(\tau) w(t-\tau) d \tau\right)=2 f_{\text {max }} \alpha
$$

O valor dessa convolução será dependente da relação entre a largura da resposta impulsiva e do sinc. Se a largura do sinc for menor que a da resposta impulsiva, dado que a área do sinc é unitária, o valor do pico será o próprio valor da resposta impulsiva. Caso contrário, o valor será menor que o da resposta impulsiva.

Além disso, utilizou-se um espectro amostrado, o que é equivalente no domínio da frequência à multiplicação do espectro por um trem de impulsos. As amostras do espectro foram calculadas com um espaçamento de $\triangle f$ o que corresponde a uma taxa de amostragem $R=\frac{1}{\triangle f}[\operatorname{amostras} / H z]$. Esse fato pode ser representado pela multiplicação do espectro por um trem de impulsos com espaçamento $\triangle f$ e amplitude 1 como visto na Figura (g). Esse trem de impulsos no domínio do tempo 
terá amplitude $\frac{1}{\triangle f}$ e espaçamento $\frac{1}{\triangle f}$, representado na Figura (h). No domínio do tempo será feita outra convolução. O resultado dessas operações pode ser visto nas Figuras (i) e (j). Essa amostragem no espectro é equivalente à periodização do sinal no tempo.

A amplitude original da resposta impulsiva chamada de $A$ foi escalonada até esse ponto em $\frac{g_{\text {pico }}}{\triangle f}$, ou $2 f_{\max } \alpha / \Delta f$
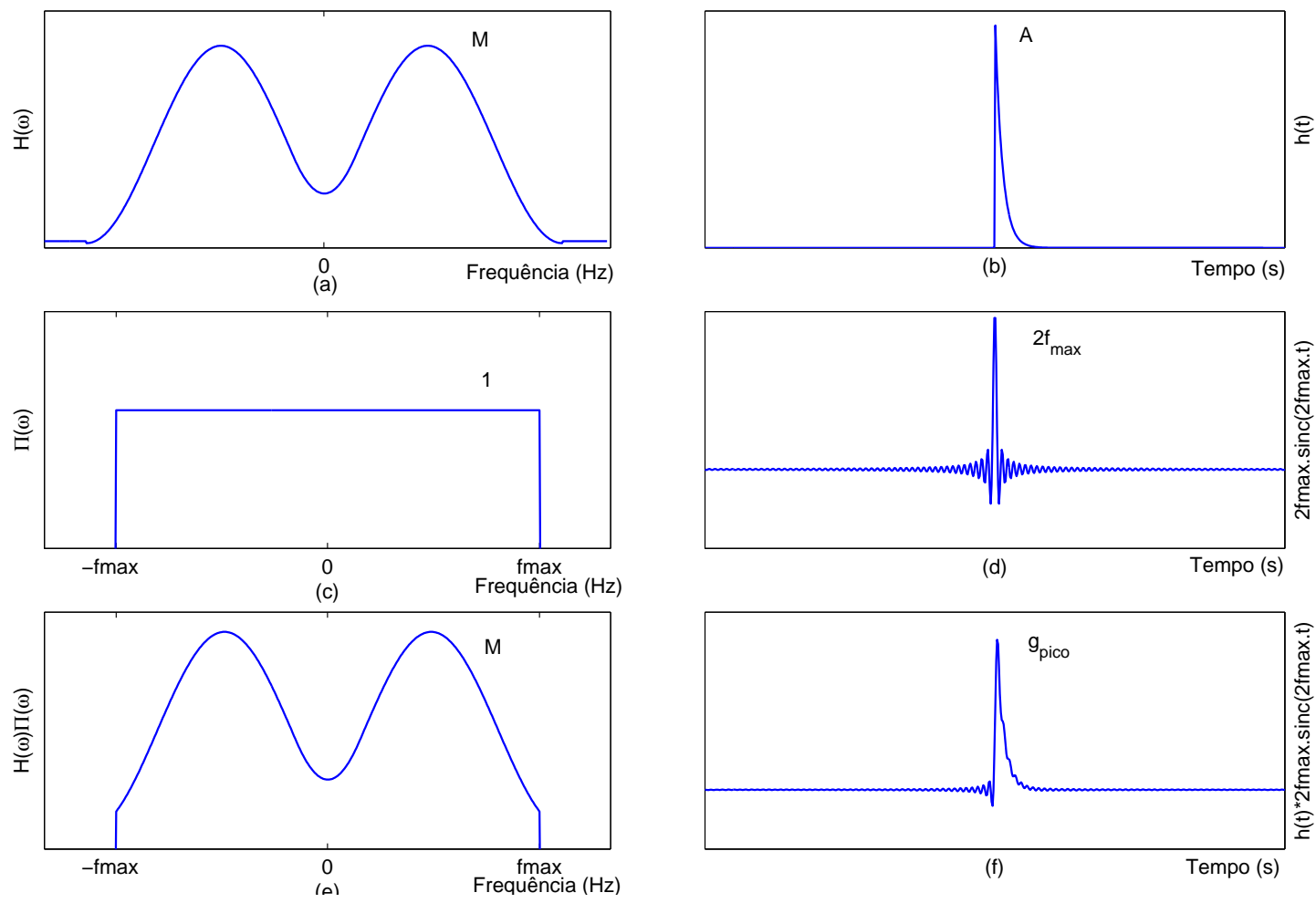

Figura 4.11: Visão geral das operações realizadas no domínio da frequência e equivalência com operações no domínio do tempo, parte 1 

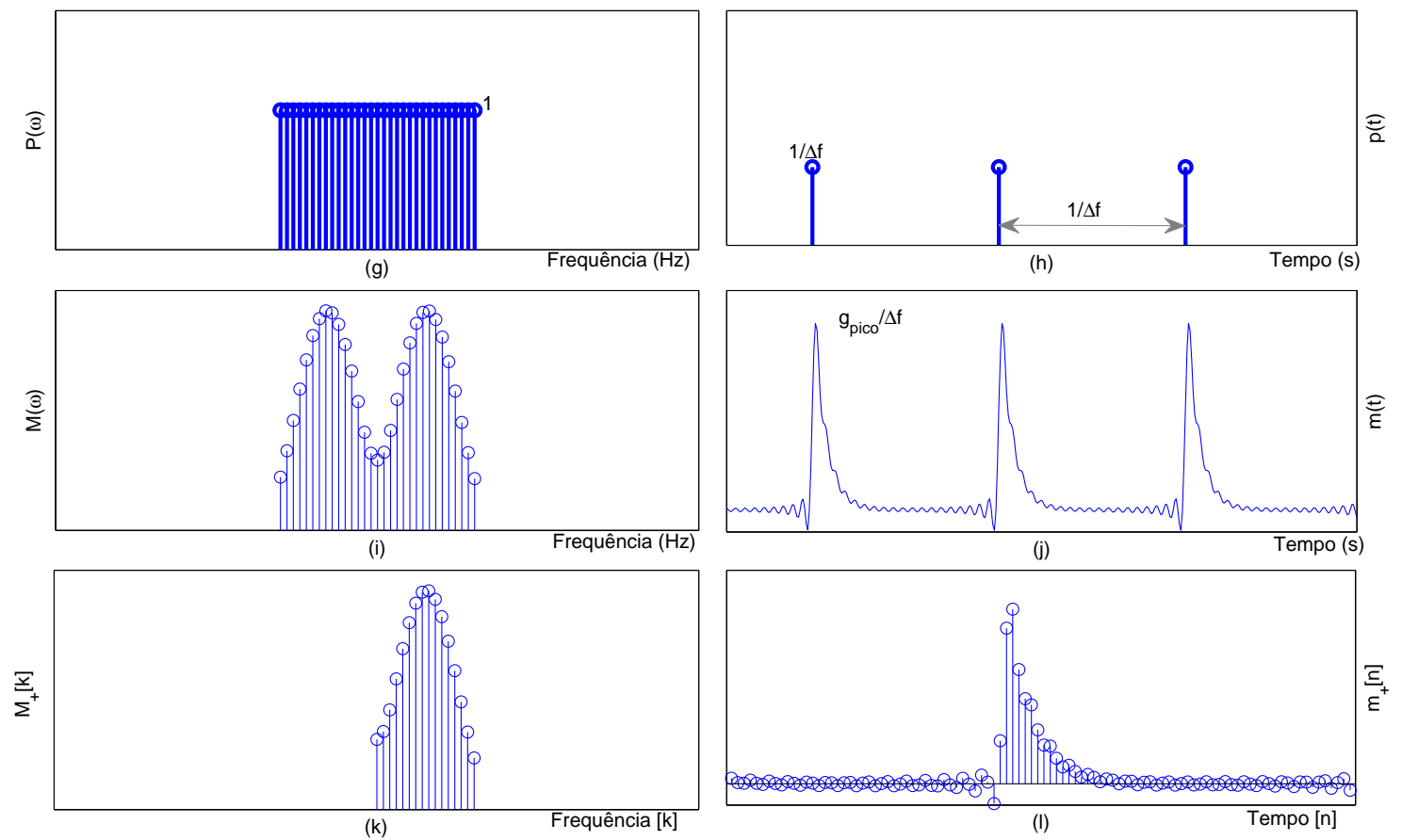

Figura 4.12: Visão geral das operações realizadas no domínio da frequência e equivalência com operações no domínio do tempo, parte 2

Levando em conta ainda que a simulação é feita somente para frequências positivas como mostrado na Figura (k), temos um espectro que é diferente de zero somente para frequências positivas. Considerando inicialmente um espectro contínuo, ou seja, dado o espectro completo $M(\omega)$, o espectro obtido por simulação é $M_{+}(\omega)=M(\omega) u(w)$.

$$
M_{+}(\omega)=\frac{1}{2} M(\omega)+\frac{1}{2} M(\omega) \operatorname{sgn}(\omega)
$$

Como demonstrado em [23], O sinal transformado $m_{+}(t)$ será

$$
m_{+}(t)=\frac{1}{2} m(t)+j m_{h}(t)
$$

Onde $m_{h}(t)$ é a transformada de Hilbert de $m(t)$. Devido à linearidade da transformada de Fourier, podemos deduzir que o sinal $m(t)$ relativo ao espectro de $M(\omega)$ pode ser obtido a partir da parte real da transformada do espectro de $M_{+}(\omega)$ como segue:

$$
m(t)=2 \operatorname{Re}\left\{\mathcal{F}^{-1}\left\{M_{+}(\omega)\right\}\right\}
$$

Para poder obter a transformada inversa do espectro $M_{+}(\omega)$, é necessário utilizar a transformada de Fourier Discreta inversa, já que não temos a expressão analítica 
do espectro e sim amostras destes em intervalos equiespaçados na frequência.

$$
m[n]=2 \operatorname{Re}\left\{\operatorname{TFDI}\left\{M_{+}[k]\right\}\right\}=2 \operatorname{Re}\left\{m_{+}[n]\right\}
$$

Portanto, a resposta impulsiva real está relacionada com o sinal obtido $m_{+}[n]$ através da TDFI da seguinte maneira:

$$
h[n] \simeq 2 \operatorname{Re}\left\{m_{+}[n]\right\} \frac{N \Delta f}{2 f_{\max } \alpha}
$$

O fator $N$ é devido ao fator de normalização da transformada inversa implementado pelo MATLAB. Considerando que $f_{\max }=N \Delta f$, temos

$$
h[n] \simeq \frac{\operatorname{Re}\left\{m_{+}[n]\right\}}{\alpha}
$$




\section{Capítulo 5}

\section{Cálculo do campo radiado a partir do modelo de carga puntiforme acelerada}

No capítulo anterior foi descrito como obter o campo elétrico e a corrente no domínio do tempo a partir de simulações no domínio da frequência. Contudo, expressões para o campo radiado por uma carga em movimento já são conhecidas da física. Dado que para transmissão pulsada um pulso de corrente percorre a antena, isso é equivalente a uma onda de perturbação na distribuição de cargas. A questão de interesse é: Seria possível utilizar as expressões de radiação de cargas para encontrar o campo radiado em uma antena? Em [11] mostrou-se que isso é possível. Se essas duas formas para encontrar o campo são equivalentes, então, no mínimo o campo radiado por um dipolo infinitesimal deve ser igual nas duas abordagens. As seções seguintes demonstram que isso é de fato o caso. Primeiramente, é calculado o campo de um dipolo infinitesimal no domínio do tempo para uma distribuição de corrente qualquer e seu significado é explorado. Em seguida, a partir da expressão do campo radiado por cargas em movimento, o campo é novamente obtido e comparado.

\subsection{Campos de um dipolo infinitesimal no domínio do tempo}

Em [11] calculou-se o campo magnético radiado devido a um elemento de corrente gaussiano. Um pulso gaussiano de corrente é do tipo

$$
i(t)=6 A \sqrt{\frac{e \pi}{3}} \frac{t}{T_{p}} e^{-6 \pi\left(\frac{t}{T_{p}}\right)^{2}}
$$


Onde $A$ é a amplitude do pulso e $T_{p}$ sua duração. Podemos encontrar o vetor potencial magnético para um elemento infinitesimal de corrente na direção $\hat{z}$, com comprimento $d l$ como segue:

$$
\vec{A}=\mu_{0} \int_{V} \frac{\vec{J}\left(\vec{r}^{\prime}, t-\frac{R^{\prime}}{c}\right) d V}{4 \pi R^{\prime}}=\frac{\mu_{0} d l}{4 \pi R} i(t-R / c) \hat{z}
$$

Onde $R^{\prime}$ é a distância do elemento de corrente até o ponto de observação e $R$ é a distância do ponto de observação até a origem. Como o elemento de corrente é infinitesimal e está centrado na origem, $R^{\prime}=R$. Dada a velocidade finita de propagação do sinal, o valor do potencial em um determinado ponto está atrasado com relação ao valor da corrente no elemento. Esse atraso é o tempo necessário para o sinal eletromagnético chegar da fonte até a posição de observação, ou seja, a distância $R$ dividida pela velocidade $c$.

Uma vez obtido o vetor potencial magnético, é possível encontrar a densidade de fluxo magnético $\vec{B}$ através do rotacional

$$
\vec{B}=\nabla \times \vec{A}
$$

Substituindo o vetor $\vec{A}$ e a corrente $i(t)$ na expressão 5.3 e transformando para coordenadas esféricas, chega-se ao seguinte resultado

$$
\begin{gathered}
\vec{B}_{r, \theta, \phi}=\left\{0,0,-\frac{e^{\frac{1}{2}-\frac{6 \pi\left(t-\frac{R}{c}\right)^{2}}{T_{p}^{2}}} d l A \sqrt{\frac{3}{\pi}}\left(12 \pi R\left(t-\frac{R}{c}\right)^{2}-c t T_{p}^{2}\right) \mu_{0} \operatorname{sen}(\theta)}{2 c R^{2} T_{p}^{3}}\right\} \\
B_{\phi}\left(t, \theta, R, T_{p}\right)=-\frac{e^{\frac{1}{2}-\frac{6 \pi\left(t-\frac{R}{c}\right)^{2}}{T_{p}{ }^{2}}} d l A \sqrt{\frac{3}{\pi}}\left(12 \pi\left(t-\frac{R}{c}\right)^{2}\right) \mu \operatorname{sen}(\theta)}{2 c R T_{p}{ }^{3}}+\frac{e^{\frac{1}{2}-\frac{6 \pi\left(t-\frac{R}{c}\right)^{2}}{T_{p}^{2}}} d l A \sqrt{\frac{3}{\pi}}\left(c t T_{p}^{2}\right) \mu \operatorname{sen}(\theta)}{2 c R^{2} T_{p}^{3}}
\end{gathered}
$$

Em [11] esse resultado foi obtido também a partir dos campos no domínio da frequência já conhecidos para um dipolo infinitesimal. A transformada inversa de Fourier foi aplicada chegando-se a exatamente à mesma expressão, na qual pode-se ver que o campo está na direção $\phi$, gira em torno do elemento de corrente que está em $\hat{z}$, como esperado. Além disso, o campo é composto de dois termos, um com decaimento $1 / R^{2}$, que representa o campo de uma corrente contínua, e um termo que decai com $1 / R$ e possui a derivada da corrente. Ou seja, para que a parcela com decaimento lento exista é necessária a variação da corrente, quanto maior essa 
variação, maior a parcela do campo com decaimento lento em função da distância.

Essas expressões para o domínio do tempo foram obtidas para um pulso Gaussiano e somente para o campo magnético. Com o objetivo de encontrar expressões para o campo elétrico e magnético de um dipolo infinitesimal com uma corrente qualquer, pode-se estender esse estudo como segue.

Seja $i(t)$ um pulso de corrente conhecido, cuja transformada de Fourier também é conhecida, $I(\omega)$. O vetor potencial magnético $\vec{A}$ devido a essa corrente, assumindo um dipolo na direção $\hat{z}$ de comprimento $d l$ é dado por:

$$
A_{z}(\vec{r}, t)=\frac{\mu_{0} d l}{4 \pi R} i\left(t-\frac{R}{c}\right) \hat{z}
$$

Ou, em coordenadas esféricas,

$$
\vec{A}_{r, \theta, \phi}=\left\{\frac{\mu_{0} d l}{4 \pi R} i\left(t-\frac{R}{c}\right) \cos \theta,-\frac{\mu_{0} d l}{4 \pi R} i\left(t-\frac{R}{c}\right) \operatorname{sen} \theta, 0\right\}
$$

onde $\vec{r}=\{R, \theta, \phi\}$ é o ponto de observação. Pode-se então calcular o campo $\vec{B}$ :

$$
\begin{gathered}
\vec{B}=\nabla \times \vec{A} \\
\vec{B}_{r, \theta, \phi}=\left\{0,0, \frac{\mu_{0} d l}{4 \pi R^{2}} i\left(t-\frac{R}{c}\right) \operatorname{sen} \theta+\frac{\mu_{0} d l}{4 \pi c R} i^{\prime}\left(t-\frac{R}{c}\right) \operatorname{sen} \theta\right\}
\end{gathered}
$$

Pode-se ver claramente a dependência do campo com a derivada da corrente dessa maneira. A derivada da corrente surge da derivação do potencial na direção $\phi$ em relação à $r$. Ou seja, o campo magnético radiado realmente varia com a derivada da corrente, enquanto o campo próximo varia com o valor da corrente. Vale ressaltar que no caso estático, onde não há variação da corrente, temos somente a primeira parcela do campo em $\phi$. É possível associar, então, a primeira parcela do campo à presença de fontes na região que geram um campo estático, já a segunda parcela do campo é devida à variação das fontes que geram um campo magnético variável.

O campo elétrico associado pode ser obtido da seguinte forma:

$$
\vec{E}=\frac{1}{\mu_{0} \epsilon_{0}} \int_{t_{0}}^{t} \nabla \times(\nabla \times \vec{A}) d t
$$

ou ainda

$$
\vec{E}=\frac{1}{\mu_{0} \epsilon_{0}} \int_{t_{0}}^{t} \nabla \times \vec{B} d t
$$

Calculando inicialmente o rotacional do campo $\vec{B}$ e multiplicando por $1 / \mu_{0} \epsilon_{0}$, 
obtém-se

$\frac{1}{\mu_{0} \epsilon_{0}} \nabla \times \vec{B}=\left\{\frac{d l \cos (\theta)}{2 \pi}\left[\frac{i(t-R / c)}{R^{3} \epsilon_{0}}+\frac{\eta i^{\prime}(t-R / c)}{R^{2}}\right], \frac{d l \operatorname{sen} \theta}{4 \pi}\left[\frac{i(t-R / c)}{R^{3} \epsilon_{0}}+\frac{\eta i^{\prime}(t-R / c)}{R^{2}}+\frac{\mu i^{\prime \prime}(t-R / c)}{R}\right], 0\right\}$

Como a corrente é a única função do tempo presente, a integral será feita somente nela, visto que o resto é uma constante no tempo

$$
\begin{gathered}
\vec{E}=\frac{1}{\mu_{0} \epsilon_{0}} \int_{t_{0}}^{t} \nabla \times \vec{B} d t \\
=\left\{\frac{d l \cos (\theta)}{2 \pi}\left[\frac{\int i(t-R / c)}{R^{3} \epsilon}+\frac{\eta i(t-R / c)}{R^{2}}\right], \frac{d l \operatorname{sen} \theta}{4 \pi}\left[\frac{\int i(t-R / c)}{R^{3} \epsilon}+\frac{\eta i(t-R / c)}{R^{2}}+\frac{\mu i^{\prime}(t-R / c)}{R}\right], 0\right\}
\end{gathered}
$$

Para verificar esse resultado para o campo elétrico, também podemos realizar a transformada de Fourier do campo de um dipolo [2]

$$
\begin{gathered}
E_{r}=\frac{\eta d l I(\omega) \cos \theta}{2 \pi R^{2}}\left[1+\frac{1}{j k R}\right] e^{-j k R} \\
E_{\theta}=\frac{j \eta d l I(\omega) k \operatorname{sen} \theta}{4 \pi R}\left[1+\frac{1}{j k R}-\frac{1}{(k R)^{2}}\right] e^{-j k R}
\end{gathered}
$$

Substituindo $k=\omega / c$, e rearranjando alguns termos, tem-se:

$$
\begin{gathered}
E_{r}=\frac{\eta d l I(\omega) \cos \theta}{2 \pi}\left[\frac{1}{R^{2}}+\frac{c}{j \omega R^{3}}\right] e^{-j \frac{\omega}{c} R} \\
E_{\theta}=\frac{j \eta d l I(\omega) \omega \operatorname{sen} \theta}{4 \pi R c}\left[1+\frac{c}{j \omega R}+\frac{c^{2}}{(j \omega R)^{2}}\right] e^{-j \frac{\omega}{c} R} \\
E_{\theta}=\frac{\eta d l I(\omega) \operatorname{sen} \theta}{4 \pi}\left[\frac{j \omega}{c R}+\frac{1}{R^{2}}+\frac{c}{j \omega R^{3}}\right] e^{-j \frac{\omega}{c} R}
\end{gathered}
$$

A exponencial à direita se traduz no domínio do tempo por um deslocamento de $t-R / c$ na função final. Dentro dos colchetes têm-se três parcelas: a primeira implica na derivada da função da corrente no domínio do tempo e possui decaimento com $1 / R$, ou seja, está relacionada à onda que se propaga para longe da fonte; a segunda será a própria transformada da função da corrente com um decaimento de $1 / R^{2}$. A terceira parcela será a integral da função da corrente devido a divisão por $j \omega$, essa parcela representa a carga que está sendo acumulada, ou seja, o campo estático. Esses campos escritos em função do tempo ficam 


$$
\begin{gathered}
E_{r}=\frac{d l \cos (\theta)}{2 \pi}\left[\frac{\eta i(t-R / c)}{R^{2}}+\frac{\int i(t-R / c)}{\epsilon_{0} R^{3}}\right] \\
E_{\theta}=\frac{d l \operatorname{sen}(\theta)}{4 \pi}\left[\frac{\mu i^{\prime}(t-R / c)}{R}+\frac{\eta i(t-R / c)}{R^{2}}+\frac{\int i(t-R / c)}{\epsilon_{0} R^{3}}\right]
\end{gathered}
$$

De fato, em [5], o elemento de corrente infinitesimal está descrito de maneira mais explícita do que em [2]. Nessa referência o elemento de corrente é na verdade composto de duas cargas, deixando claro que os termos com decaimento $1 / R^{3}$ são do campo de um dipolo estático. O campo estático de um dipolo é dado por [5], considerando $d l / R \ll 1$ :

$$
\begin{gathered}
E_{r_{\text {estatico }}}=\frac{2 p \cos (\theta)}{4 \pi \epsilon_{0} R^{3}}=\frac{q d l \cos (\theta)}{2 \pi \epsilon_{0} R^{3}} \\
E_{\theta_{\text {estatico }}}=\frac{p \operatorname{sen}(\theta)}{4 \pi \epsilon_{0} R^{3}}=\frac{q d l \operatorname{sen}(\theta)}{4 \pi \epsilon_{0} R^{3}}
\end{gathered}
$$

Onde $p=q d l$ é o momento do dipolo, q é o valor de uma das cargas e $d l$ a distância entre elas. Comparando o campo de um dipolo estático com a terceira parcela obtida anteriormente, obtém-se

$$
\begin{aligned}
& E_{r}=\frac{d l \cos (\theta)}{2 \pi} \frac{\int i(t-R / c)}{\epsilon_{0} R^{3}}=\frac{q d l \cos (\theta)}{2 \pi \epsilon_{0} R^{3}} \\
& E_{\theta}=\frac{d l \operatorname{sen}(\theta)}{4 \pi} \frac{\int i(t-R / c)}{\epsilon_{0} R^{3}}=\frac{q d l \operatorname{sen}(\theta)}{4 \pi \epsilon_{0} R^{3}}
\end{aligned}
$$

Levando em conta que a integral da corrente é a carga acumulada, tem-se a equivalência das expressões. Para explorar o real significado de cada termo dos dois campos no domínio do tempo, pode-se considerar três casos. No primeiro a carga está parada. Nesse caso, os campos serão:

$$
\begin{gathered}
B_{\phi}=0 \\
E_{r}=\frac{p \cos (\theta)}{2 \pi \epsilon_{0} R^{3}} \\
E_{\theta}=\frac{q d l \operatorname{sen}(\theta)}{4 \pi \epsilon_{0} R^{3}}
\end{gathered}
$$

Nesse caso não há campo magnético, somente o campo elétrico, que é idêntico ao campo de um dipolo estático. Para o segundo caso, pode-se considerar a corrente 
constante. Portanto, os campos serão:

$$
\begin{gathered}
B_{\phi}=\frac{\mu_{0} d l}{4 \pi R^{2}} i\left(t-\frac{R}{c}\right) \operatorname{sen}(\theta) \\
E_{r}=\frac{d l \cos \theta}{2 \pi}\left[\frac{\eta i(t-R / c)}{R^{2}}+\frac{\int i(t-R / c)}{\epsilon_{0} R^{3}}\right] \\
E_{\theta}=\frac{d l \operatorname{sen}(\theta)}{4 \pi}\left[\frac{\eta i(t-R / c)}{R^{2}}+\frac{\int i(t-R / c)}{\epsilon_{0} R^{3}}\right]
\end{gathered}
$$

Assim, devido à corrente que não varia no tempo, surge um novo fator do campo elétrico que decai devido à $1 / R^{2}$. Esse fator também é proporcional à corrente, ou seja, à derivada da carga, todas as parcelas dos campos com exceção das que decaem com $1 / R$ já estão presentes devido a um elemento de corrente constante. Por isso, pode-se dizer que o campo próximo é um efeito estático no sentido que ele já está presente no caso de corrente constante. Ou seja, o campo elétrico com decaimento de $1 / R^{2}$ é um efeito magnetostático e está presente em qualquer elemento que conduza corrente constante, não sendo específico às antenas.

No terceiro caso, tem-se uma corrente variável, nesse caso, aparecem todas as parcelas, como segue:

$$
\begin{gathered}
B_{\phi}=\frac{d l}{4 \pi} \operatorname{sen} \theta\left[\frac{\mu_{0}}{R^{2}} i\left(t-\frac{R}{c}\right)+\frac{1}{\epsilon_{0} R} i^{\prime}\left(t-\frac{R}{c}\right)\right] \\
E_{r}=\frac{d l \cos \theta}{2 \pi}\left[\frac{\eta i(t-R / c)}{R^{2}}+\frac{\int i(t-R / c)}{\epsilon_{0} R^{3}}\right] \\
E_{\theta}=\frac{d l \operatorname{sen} \theta}{4 \pi}\left[\frac{\mu i^{\prime}(t-R / c)}{R}+\frac{\eta i(t-R / c)}{R^{2}}+\frac{\int i(t-R / c)}{\epsilon_{0} R^{3}}\right]
\end{gathered}
$$

Uma derivação interessante também é feita em [5], onde é utilizado um dipolo com duas cargas $+e$ e $-e$ separadas pela distância $d l$. A carga total se conserva e é sempre zero. Para um dipolo infinitesimal temos $d l \rightarrow 0$ e $e \rightarrow \infty$ de modo que o momento do dipolo $p=e d l$, seja finito. A corrente é dada por $I=d e / d t$. Nessa formulação os campos são:

$$
\begin{aligned}
& H_{\phi}=\frac{1}{4 \pi} \operatorname{sen} \theta\left[\frac{\dot{p}}{R^{2}}+\frac{\ddot{p}}{c R}\right] \\
& E_{r}=\frac{\eta \cos \theta)}{2 \pi}\left[\frac{c p}{R^{3}}+\frac{\dot{p}}{R^{2}}\right]
\end{aligned}
$$




$$
E_{\theta}=\frac{\eta \operatorname{sen}(\theta)}{4 \pi}\left[\frac{c p}{R^{3}}+\frac{\dot{p}}{R^{2}}+\frac{\ddot{p}}{c R}\right]
$$

Percebe-se então que os resultados são exatamente iguais.

\subsection{Campos radiados por um dipolo infinitesimal a partir do modelo de radiação de uma carga acelerada}

Na seção anterior, constatou-se que os campos radiados para um elemento de corrente no domínio do tempo são:

$$
\begin{gathered}
B_{\phi}=\frac{L}{4 \pi} \operatorname{sen}(\theta) \frac{1}{\epsilon_{0} r} i^{\prime}\left(t-\frac{r}{c}\right) \\
E_{\theta}=\frac{L \operatorname{sen}(\theta)}{4 \pi} \frac{\mu i^{\prime}(t-r / c)}{r}
\end{gathered}
$$

Deseja-se verificar se as expressões para a radiação de um dipolo infinitesimal são equivalentes ao campo radiado por uma carga em movimento. Nesse caso, o elemento infinitesimal de corrente é uma carga $q$ que se move com velocidade $v$ que pode ou não ser função do tempo e possui aceleração $a$. Como o elemento de corrente está na direção $\hat{z}$, a velocidade e a aceleração estarão na mesma direção.

Considerando um elemento de corrente

$$
i=\lambda v=\frac{q}{d l} v
$$

é possivel encontrar a aceleração pela sua derivada

$$
\begin{gathered}
\frac{d i}{d t}=\frac{q}{d l} \frac{d v}{d t}=\frac{q}{d l} a \\
a=\frac{d l}{q} \frac{d i}{d t}
\end{gathered}
$$

O campo radiado por uma carga em movimento será

$$
\vec{E}_{a}(\vec{r}, t)=\frac{q}{4 \pi \varepsilon_{0} c^{2}}\left\{\frac{\hat{R}_{q} \times\left[\hat{R}_{q} \times \vec{a}\right]}{R_{q}}\right\}_{t r}
$$

Onde $\vec{R}_{q}$ é o vetor ligando a carga ao ponto de observação, $\hat{R}_{q}$ é o versor nessa direção e $t r$ indica que o instante de tempo a ser considerado é $t-R_{q} / c$. A aceleração 
é devida somente à variação temporal da corrente. Considerando $\vec{R}_{q}=\{R, \theta, \phi\}_{\text {esf }}$, $\hat{R}_{q}=\{1, \theta, \phi\}_{\text {esf }}=\{x, y, z\}_{\text {cartesianas }}=\{\sin (\theta) \cos (\phi), \sin (\theta) \sin (\phi), \cos (\theta)\}$ e $\vec{a}=$ $\left\{0,0, \frac{d l}{q} \frac{d i}{d t}\right\}_{\text {cartesianas }}$.

$$
\begin{gathered}
\hat{R}_{q} \times \vec{a}=\left\{\frac{d l}{q} \frac{d i}{d t} \sin (\theta) \sin (\phi),-\frac{d l}{q} \frac{d i}{d t} \sin (\theta) \cos (\phi), 0\right\} \\
\hat{R}_{q} \times\left(\hat{R}_{q} \times \vec{a}\right)=\left\{\frac{d l}{q} \frac{d i}{d t} \cos (\phi) \cos (\theta) \sin (\theta), \frac{d l}{q} \frac{d i}{d t} \cos (\theta) \sin (\phi) \sin (\theta),-\frac{d l}{q} \frac{d i}{d t} \sin ^{2}(\theta)\right\}
\end{gathered}
$$

E utilizando a matriz de transformação de vetores de coordenadas cartesianas para esféricas:

$$
\hat{R}_{q} \times\left(\hat{R}_{q} \times \vec{a}\right)=\left\{0, \frac{d l}{q} \frac{d i}{d t} \sin (\theta), 0\right\}
$$

e substituindo na expressão do campo,

$$
\begin{gathered}
\vec{E}_{a}(\vec{r}, t)=\frac{q}{4 \pi \varepsilon_{0} c^{2}}\left\{\frac{\left\{0, \frac{d l}{q} \frac{d i}{d t} \sin (\theta), 0\right\}}{R}\right\}_{t r} \\
E_{\theta}=\frac{1}{4 \pi R \varepsilon_{0} c^{2}} d l \frac{d i}{d t} \sin (\theta) \\
E_{\theta}=\frac{\mu d l}{4 \pi R} \frac{d i}{d t} \sin (\theta)
\end{gathered}
$$

Da mesma forma, para o campo densidade de fluxo magnético,

$$
\begin{gathered}
\vec{B}_{a}(\vec{r}, t)=-\frac{\mu q}{4 \pi c}\left\{\frac{\hat{R}_{q} \times \vec{a}}{R}\right\}_{t r} \\
\vec{B}_{a}(\vec{r}, t)=-\frac{\mu q}{4 \pi c R}\left\{0,0,-\frac{d l}{q} \frac{d i}{d t} \sin (\theta)\right\}_{t r} \\
B_{\phi}=\frac{\mu q d l}{4 \pi c R} \frac{d i}{d t} \sin (\theta)=\frac{d l \sin (\theta)}{4 \pi r R \varepsilon} \frac{d i}{d t}
\end{gathered}
$$

As expressões obtidas são as mesmas que foram obtidas para o dipolo infinitesimal, o que indica a equivalência e a validade de se utilizar essas expressões para o cálculo do campo radiado. As expressões originais para o cálculo do campo radiado por um dipolo são convenientes quando o elemento de corrente está parado e possui uma variação na sua intensidade, enquanto as expressões em função da carga são melhores para os casos nos quais a intensidade da distribuição de carga 
é aproximadamente constante porém se move no espaço. Por isso, as primeiras são mais convenientes em regime permanente senoidal pois, todos os pontos da antena estão radiando todo o tempo, enquanto na transmissão pulsada somente alguma região da antena terá corrente em um determinado momento.

Vale observar que, apesar de o campo radiado ser o mesmo nos dois casos, o campo próximo não o é. Primeiramente porque no caso do dipolo se supõe duas cargas cuja carga total é nula, e no caso estudado considerou-se um elemento de corrente que na verdade se trata de uma distribuição de carga variável e a carga total não é nula. Do ponto de vista do campo distante porém, os dois são equivalentes.

Em antenas e guias de onda no domínio do tempo, as duas cargas opostas estarão uma em cada fio não podendo ser aproximadas por um dipolo infinitesimal, nesse caso o modelo com as cargas é mais adequado pois pode-se compor as cargas e as correntes como desejado, em função da geometria. 


\section{Capítulo 6}

\section{Estudo da antena espiral equiangular}

Em [11], foi mostrado que o modelo de carga acelerada podia ser utilizado para aproximar a forma de onda radiada do campo elétrico. Porém, nenhuma consideração foi feita com relação ao seu valor absoluto. Neste primeiro modelo, também foi suposta que a carga era constante, ou seja, não havia variação da amplitude do pulso em função da posição. O cálculo do campo foi feito utilizando um programa desenvolvido em Matlab. Como entrada, esse programa aceitava as coordenadas numéricas da antena e calculava os valores da velocidade e da aceleração, através da diferença entre as amostras divididas pelo tempo decorrido entre duas amostras. Por fim, todos os valores de campo radiados em um mesmo intervalo são agrupados, formando o campo radiado em um determinado instante.

Deseja-se verificar a extensão da validade desse modelo para o campo radiado, incluindo corrente variável. Para tanto, em primeiro lugar, é necessário obter a expressão analítica para o decaimento da corrente na antena para, em seguida, utilizá-la e aprimorar a aproximação do campo. Os campos elétricos simulado e analítico, que antes se correspondiam normalizados, agora devem se corresponder em valor absoluto.

Para isso, a forma utilizada para computar o campo analítico foi alterada. Com o refinamento do modelo, a estimativa da radiação em outras direções foi aprimorada. O programa em Matlab foi substituído por um programa no Mathematica onde a carga pode percorrer qualquer trajetória e o campo gerado em um determinado ponto é computado. Esse modelo é todo analítico, ou seja, possui como entrada as coordenadas da antena em função do tempo $\{x(t), y(t), z(t)\}$, e calcula o campo elétrico também em função do tempo e da posição da antena. Em seguida, é necessário fazer uma tabela relacionando o campo que foi radiado com o tempo de chegada no ponto de observação. Finalmente, os campos que chegam no mesmo intervalo são agrupados, transferidos para o Matlab e comparados com os campos 
simulados e transformados no tempo, como mostrado no capítulo da Metodologia.

Dessa maneira, é possível, somente através das coordenadas da antena, calcular a resposta impulsiva da antena para a corrente e para o campo elétrico. Os efeitos da distorção foram desprezados. De fato, o campo previsto desconsiderando os efeitos da distorção já está satisfatoriamente próximo ao campo simulado.

\subsection{Equação da antena espiral equiangular}

A antena espiral equiangular é uma antena interessante pois possui um diagrama de radiação independente da frequência [6]. Uma espiral no plano está completamente determinada pelo seu raio inicial $\rho_{0}$ e pela sua taxa de expansão $1 / b$. A partir desses dois parâmetros, pode-se variar livremente o ângulo $\phi$ e obter o valor do raio, construindo a espiral. O raio é obtido de acordo com a seguinte equação [2]:

$$
\rho= \begin{cases}\rho_{0} e^{b\left(\phi-\phi_{0}\right)} & \theta=\pi / 2 \\ 0 & \text { c.c. }\end{cases}
$$

Outra forma da equação 6.1 pode ser obtida agrupando os termos independentes de $\phi$. Nesse caso, fazendo $M=\rho_{0} e^{b\left(-\phi_{0}\right)}$, temos:

$$
\rho= \begin{cases}M e^{b \phi} & \theta=\pi / 2 \\ 0 & \text { c.c. }\end{cases}
$$

Se desejarmos construir a espiral usando o raio como variável, podemos também escrever a expressão de $\phi$ em função de $\rho$, como segue:

$$
\phi=\frac{1}{b} \ln \left(\frac{\rho}{M}\right)
$$

O comprimento $l$ da antena espiral é equivalente ao tamanho do fio necessário para se construir a mesma. O comprimento de uma curva qualquer em coordenadas esféricas é dado por [2], para calculá-lo é necessário o raio inicial $\rho_{0}$ e o raio final $\rho_{1}$, como segue:

$$
l=\int_{\rho_{0}}^{\rho_{1}}\left[\rho^{2}\left(\frac{d \phi}{d \rho}\right)^{2}+1\right]^{1 / 2} d \rho
$$

Primeiramente calcula-se $\frac{d \phi}{d \rho}$ usando 6.3:

$$
\frac{d \phi}{d \rho}=\frac{1}{b} \frac{M}{\rho} \frac{1}{M}=\frac{1}{b \rho}
$$


E o comprimento será

$$
l=\int_{\rho_{0}}^{\rho_{1}}\left[\rho^{2}\left(\frac{1}{b \rho}\right)^{2}+1\right]^{1 / 2} d \rho=\int_{\rho_{0}}^{\rho_{1}}\left[\frac{1}{b^{2}}+1\right]^{1 / 2} d \rho=\left(\rho_{1}-\rho_{0}\right) \sqrt{1+\frac{1}{b^{2}}}
$$

Para se ter o comprimento da espiral para qualquer posição, basta deixar o raio final como variável, ou seja, $\rho$, e respeitar a condição $\rho>\rho_{0}$. Chegando a

$$
l=\left(\rho-\rho_{0}\right) \sqrt{1+\frac{1}{b^{2}}}
$$

Essa relação bijetora entre $l$ e $\rho$ permite escrever novas funções para $\rho$ e $\phi$ em função do parâmetro $l$. Isso é útil pois $l$ pode ser muito bem aproximado por uma relação linear com o tempo, $l=c t$, servindo para descrever pulsos que se propagam com a velocidade da luz na antena. Além disso, ao usar $l$ como parâmetro independente, será possível comparar de maneira mais direta os resultados analíticos com os resultados obtidos por simulação. As novas expressões para $\rho$ e $\phi$ em função de $l$ são

$$
\begin{gathered}
\rho(l)=\frac{l}{\sqrt{1+\frac{1}{b^{2}}}}+\rho_{0} \\
\phi(l)=\frac{1}{b} \ln \left(\frac{\rho(l)}{M}\right)=\frac{1}{b} \ln \left(\frac{\frac{l}{\sqrt{1+\frac{1}{b^{2}}}}+\rho_{0}}{\rho_{0} e^{-b \phi_{0}}}\right)=\frac{1}{b} \ln \left(\frac{l}{\rho_{0} \sqrt{1+\frac{1}{b^{2}}}}+1\right)+\phi_{0}
\end{gathered}
$$

\subsection{Equação da antena espiral simulada}

As expressões anteriores foram obtidas para uma espiral genérica. Pode-se então adaptá-la à espiral simulada. A espiral simulada foi projetada usando as expressões anteriores com $b=0,424734, \phi=0$ e $\rho_{0}=0,01$. Os dois braços da espiral foram unidos por um segmento que contém a fonte. No caso da espiral em questão a distância entre o início dos braços da espiral é de 0,02m. Para reduzir essa distância, os dois braços foram deslocados em $d=0,01 \mathrm{~m}$ em direção ao centro na direção $x$ e unidos por um seguimento que contém a fonte de corrente. O comprimento do segmento da fonte é $h$. A Figura 6.1 demonstra essa alteração. 


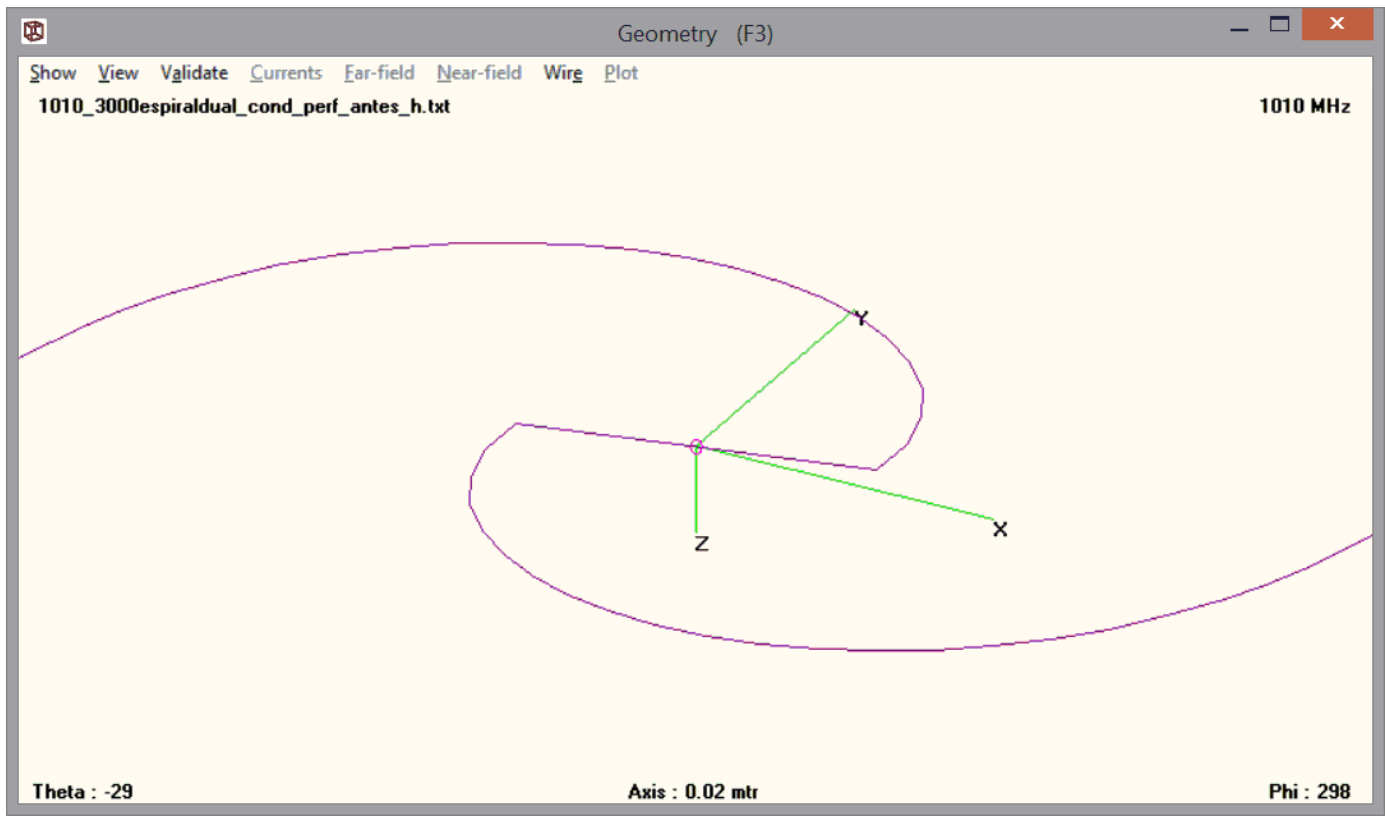

(a) Espiral antes do deslocamento $d$

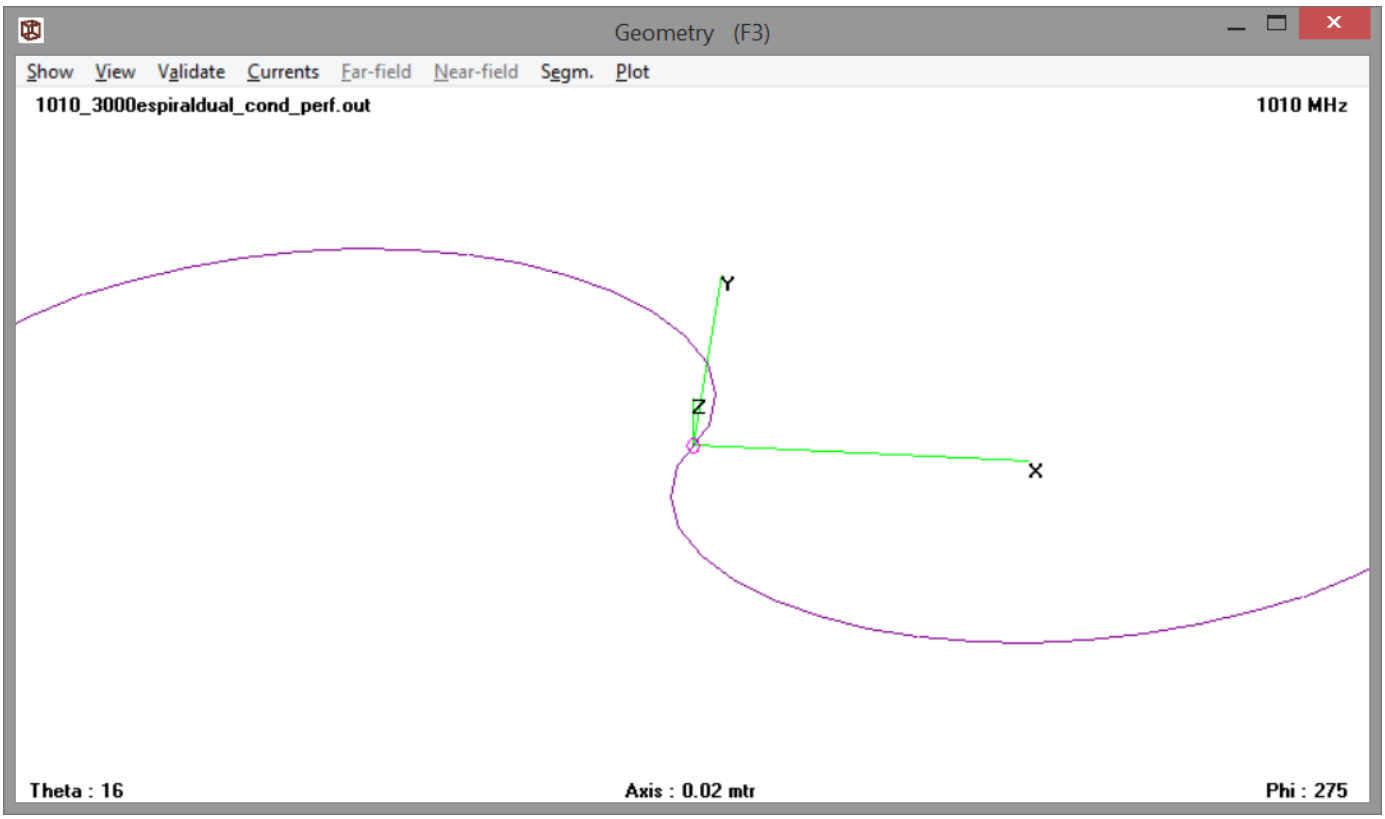

(b) Espiral após o deslocamento $d$

Figura 6.1: Ilustração da modificação antena para redução das reflexões na fonte

Deseja-se obter uma expressão analítica para a espiral simulada. Para tanto, pode-se considerar que, em um determinado instante de tempo $t$, o pulso de carga percorreu a distância $l=c t$. Essa distância, descrita a partir da geometria da antena espiral, será 


$$
l=c t=\underbrace{\int_{\rho_{0}}^{\rho_{1}}\left[\rho^{2}\left(\frac{d \phi}{d \rho}\right)^{2}+1\right]^{1 / 2} d \rho}_{\text {Trajeto espiral }}+\underbrace{h}_{\text {Trajeto fonte }}
$$

Para $t=0$, o pulso está na fonte. Para $t=h / c$, o pulso terminou de percorrer o segmento e finalmente, para um $t>h / c$, o pulso está percorrendo o braço da espiral. Ou seja, para $l>h$, o pulso estará seguindo a trajetória determinada pela espiral. O trajeto da fonte $h$, foi tomado como o maior comprimento do segmento da fonte que é dado na menor frequência. A figura 6.2 ilustra o maior trajeto $h$.

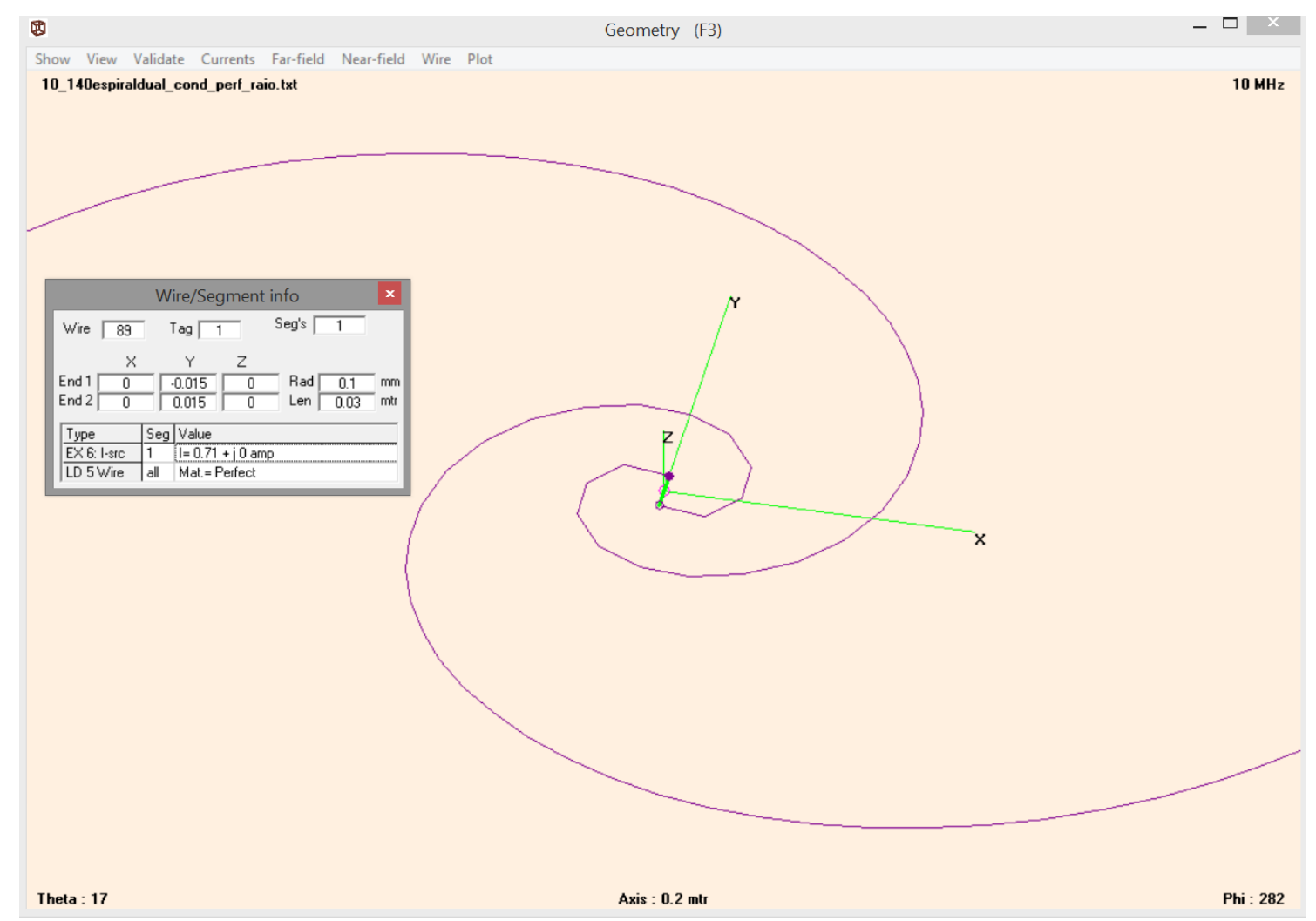

Figura 6.2: Comprimento da fonte $h$ usado como condição inicial

As coordenadas cartesianas da espiral são dadas por

$$
\begin{gathered}
x=\rho(l) \cos (\phi(l))-d \\
y=\rho(l) \sin (\phi(l))
\end{gathered}
$$

$$
z=0
$$


As expressões de $\rho(l)$ e $\phi(l)$ para a espiral simulada se tornam

$$
\begin{gathered}
l=\left(\rho-\rho_{0}\right) \sqrt{1+\frac{1}{b^{2}}}+h \\
\rho(l)=\frac{l-h}{\sqrt{1+\frac{1}{b^{2}}}}+\rho_{0}, \quad l>h \\
\phi(l)=\frac{1}{b} \ln \left(\frac{l-h}{\rho_{0} \sqrt{1+\frac{1}{b^{2}}}}+1\right)+\phi_{0}, \quad l>h
\end{gathered}
$$

Para conferir se essas expressões correspondiam realmente à espiral simulada, as coordenadas presentes no arquivo de saída da simulação e as coordenadas calculadas analiticamente para os dois braços da espiral, usando o software Mathematica, foram comparadas, resultando na Figura 6.3. Nessa Figura, Analítico 1 corresponde ao primeiro braço e Analítico 2 corresponde ao segundo braço. A única diferença entre os dois é o ângulo inicial $\phi_{0}$. Enquanto que, para primeiro braço $\phi_{0}=0$, para o segundo braço $\phi_{0}=\pi$. (Anteriormente pegou-se diretamente as coordenadas no arquivo do NEC) 


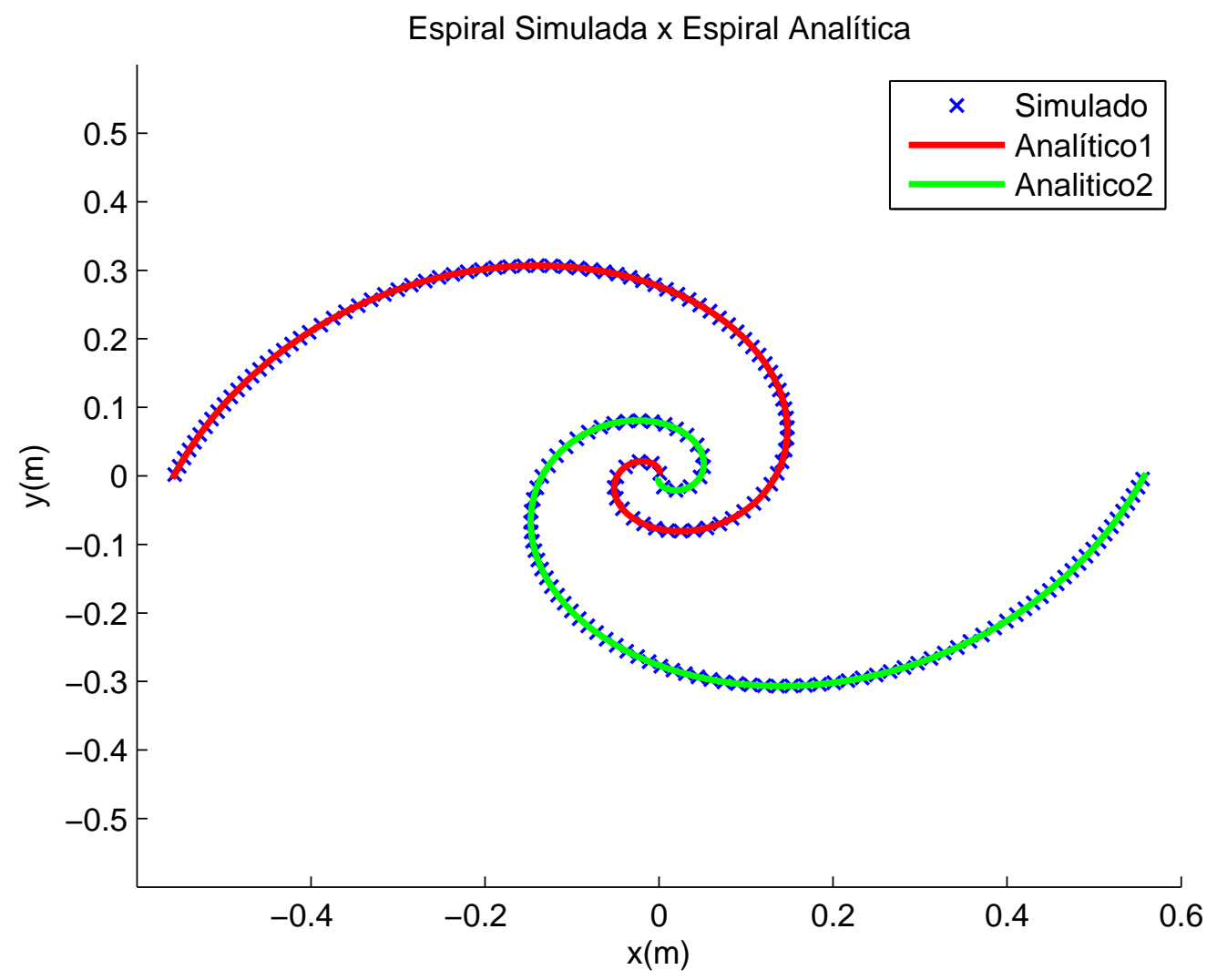

Figura 6.3: Conferência das expressões analíticas obtidas para a antena espiral simulada

\subsection{Aceleração centrípeta em coordenadas esféricas}

A radiação ocorre devido à aceleração de cargas. Portanto, para conhecer o campo radiado é necessário conhecer a aceleração que é imposta ao pulso de carga pela antena. No caso de uma antena filamentar e um pulso que se propaga com a velocidade da luz, a aceleração imposta será a aceleração causada pela própria geometria da antena. Seja uma carga que percorre uma trajetória dada em coordenadas esféricas por $(r, \theta, \varphi)$. A aceleração em coordenadas esféricas pode ser calculada como segue

$$
\begin{gathered}
a_{r}=\left(\ddot{r}-r \dot{\varphi}^{2}-r \dot{\theta}^{2} \sin ^{2}(\varphi)\right) \hat{e}_{r} \\
a_{\theta}=(2 \dot{r} \dot{\theta} \sin (\varphi)+2 r \dot{\theta} \dot{\varphi} \cos (\varphi)+r \ddot{\theta} \sin (\varphi)) \hat{e}_{\theta} \\
a_{\varphi}=\left(2 \dot{r} \dot{\varphi}+r \ddot{\varphi}-r \dot{\theta}^{2} \sin (\varphi) \cos (\varphi)\right) \hat{e}_{\varphi}
\end{gathered}
$$


No caso da espiral, $r=\rho(l)=\rho(c t), \varphi=\phi(l)=\phi(c t)$ e $\theta=\pi / 2$ é uma constante e portanto todas as suas derivadas são nulas. Inserindo essa condição nas equações acima temos:

$$
\begin{gathered}
a_{\rho}=\left(\ddot{\rho}-\rho \dot{\phi}^{2}\right) \hat{e}_{\rho} \\
a_{\theta}=0 \\
a_{\phi}=(2 \dot{\rho} \dot{\phi}+\rho \ddot{\phi}) \hat{e}_{\phi}
\end{gathered}
$$

Como o raio da espiral equiangular é diretamente proporcional ao tempo, a sua segunda derivada será nula sendo possível simplificar ainda mais a aceleração:

$$
\vec{a}=\rho \dot{\phi}^{2} \hat{e}_{\rho}+(2 \dot{\rho} \dot{\phi}+\rho \ddot{\phi}) \hat{e}_{\phi}
$$

As expressões para $\rho$ e $\phi$ em função de $t$ se tornam

$$
\begin{gathered}
\rho(c t)=\frac{c t-h}{\sqrt{1+\frac{1}{b^{2}}}}+\rho_{0}, \quad t>h / c \\
\phi(c t)=\frac{1}{b} \ln \left(\frac{c t-h}{\rho_{0} \sqrt{1+\frac{1}{b^{2}}}}+1\right)+\phi_{0}, \quad t>h / c
\end{gathered}
$$

e suas derivadas primeiras são

$$
\begin{gathered}
\dot{\rho}(c t)=\frac{c}{\sqrt{1+\frac{1}{b^{2}}}}, t>h / c \\
\dot{\phi}(c t)=\frac{1}{b\left(\frac{c t-h}{\rho_{0} \sqrt{1+\frac{1}{b^{2}}}}+1\right)} \frac{c}{\rho_{0} \sqrt{1+\frac{1}{b^{2}}}}, t>h / c \\
\dot{\phi}(c t)=\frac{1}{b\left(\frac{c t-h}{\sqrt{1+\frac{1}{b^{2}}}}+\rho_{0}\right)} \frac{c}{\sqrt{1+\frac{1}{b^{2}}}}, t>h / c
\end{gathered}
$$

e suas derivadas segundas

$$
\ddot{\rho}=0
$$




$$
\begin{aligned}
& \ddot{\phi}(c t)=\frac{-1}{b\left(\frac{c t-h}{\sqrt{1+\frac{1}{b^{2}}}}+\rho_{0}\right)^{2}}\left(\frac{c}{\sqrt{1+\frac{1}{b^{2}}}}\right)^{2}, t>h / c \\
& a_{\rho}=\left(\frac{c t-h}{\sqrt{1+\frac{1}{b^{2}}}}+\rho_{0}\right)\left(\frac{1}{b\left(\frac{c t-h}{\sqrt{1+\frac{1}{b^{2}}}}+\rho_{0}\right)} \frac{c}{\sqrt{1+\frac{1}{b^{2}}}}\right)^{2}=\frac{1}{b^{2}\left(\frac{c t-h}{\sqrt{1+\frac{1}{b^{2}}}}+\rho_{0}\right)} \frac{c^{2}}{1+\frac{1}{b^{2}}} \\
& a_{\rho}=\frac{c^{2}}{\left(b^{2}+1\right)\left(\frac{c t-h}{\sqrt{1+\frac{1}{b^{2}}}}+\rho_{0}\right)}=\frac{\sqrt{1+\frac{1}{b^{2}}} c^{2}}{\left(1+b^{2}\right)\left(c t-h+\sqrt{1+\frac{1}{b^{2}}} \rho_{0}\right)} \\
& a_{\phi}=\left(2 \frac{c}{\sqrt{1+\frac{1}{b^{2}}}}\left(\frac{1}{b \frac{c t-h}{\sqrt{1+\frac{1}{b^{2}}}}+\rho_{0}} \frac{c}{\sqrt{1+\frac{1}{b^{2}}}}\right)+\left(\frac{c t-h}{\sqrt{1+\frac{1}{b^{2}}}}+\rho_{0}\right) \frac{-1}{b\left(\frac{c t-h}{\sqrt{1+\frac{1}{b^{2}}}}+\rho_{0}\right)^{2}}\left(\frac{c}{\sqrt{1+\frac{1}{b^{2}}}}\right)^{2}\right) \\
& a_{\phi}=2 \frac{c^{2}}{1+\frac{1}{b^{2}}} \frac{1}{b\left(\frac{c t-h}{\sqrt{1+\frac{1}{b^{2}}}}+\rho_{0}\right)}+\frac{-1}{b\left(\frac{c t-h}{\sqrt{1+\frac{1}{b^{2}}}}+\rho_{0}\right)} \frac{c^{2}}{1+\frac{1}{b^{2}}} \\
& a_{\phi}=2 \frac{c^{2} b^{2}}{1+b^{2}} \frac{1}{b\left(\frac{c t-h}{\sqrt{1+\frac{1}{b^{2}}}}+\rho_{0}\right)}+\frac{-1}{b\left(\frac{c t-h}{\sqrt{1+\frac{1}{b^{2}}}}+\rho_{0}\right)} \frac{c^{2} b^{2}}{1+b^{2}} \\
& a_{\phi}=2 \frac{c^{2} b}{1+b^{2}} \frac{1}{\left(\frac{c t-h}{\sqrt{1+\frac{1}{b^{2}}}}+\rho_{0}\right)}+\frac{-1}{\left(\frac{c t-h}{\sqrt{1+\frac{1}{b^{2}}}}+\rho_{0}\right)} \frac{c^{2} b}{1+b^{2}} \\
& a_{\phi}=\frac{c^{2} b}{1+b^{2}} \frac{1}{\left(\frac{c t-h}{\sqrt{1+\frac{1}{b^{2}}}}+\rho_{0}\right)}=\frac{\sqrt{1+\frac{1}{b^{2}}} b c^{2}}{\left(1+b^{2}\right)\left(c t-h+\sqrt{1+\frac{1}{b^{2}}} \rho_{0}\right)}
\end{aligned}
$$

E substituindo na expressão para a aceleração resulta, em função de $l=c t$, 


$$
\vec{a}=\frac{\sqrt{1+\frac{1}{b^{2}}} c^{2}}{\left(1+b^{2}\right)\left(l-h+\sqrt{1+\frac{1}{b^{2}}} \rho_{0}\right)} \hat{e}_{r}+\frac{\sqrt{1+\frac{1}{b^{2}}} b c^{2}}{\left(1+b^{2}\right)\left(l-h+\sqrt{1+\frac{1}{b^{2}}} \rho_{0}\right)} \hat{e}_{\phi}
$$

Ou, em função do raio,

$$
\vec{a}=\frac{c^{2}}{\left(1+b^{2}\right) \rho(l)} \hat{e}_{\rho}+\frac{b c^{2}}{\left(1+b^{2}\right) \rho(l)} \hat{e}_{\varphi}
$$

Como os versores $\hat{e}_{r}$ e $\hat{e}_{\phi}$ são ortonormais, é possível obter o módulo da aceleração ao quadrado como segue

$$
|\vec{a}|^{2}=\frac{c^{4}}{\left(1+b^{2}\right) \rho^{2}(l)}=\frac{c^{4}}{b^{2}\left(l-h+\sqrt{1+\frac{1}{b^{2}}} \rho_{0}\right)^{2}}
$$

A aceleração centrípeta é a velocidade ao quadrado dividida pelo raio de curvatura. No caso da antena espiral equiangular, o raio de curvatura é proporcional à própria coordenada $\rho$ da antena, como pode ser visto na expressão 6.40. Ou seja, a aceleração é inversamente proporcional ao raio de curvatura que por sua vez é proporcional ao comprimento $l$.

Em [11] foi mostrado que o pulso se propaga com a velocidade constante igual à velocidade da luz. Portanto, a única aceleração restante é a aceleração centrípeta. Por isso, para saber quantitativamente quanto foi radiado é necessário utilizar um procedimento genérico de cálculo da aceleração centrípeta.

\subsection{Expressão para corrente em função do raio de curvatura}

O pulso de carga se propaga com velocidade constante e, portanto, a única aceleração presente é a aceleração centrípeta. A aceleração centrípeta foi calculada em função do comprimento e dos parâmetros geométricos da antena. A potência radiada pode ser calculada a partir do campo radiado ou campo de aceleração como feito em [36]. Ela é dada por

$$
P(t)=\frac{q^{2} a_{c}^{2}(t)}{6 \pi \varepsilon_{0} c^{3}}
$$

Sendo $P(t)$ a potência radiada por uma onda de carga, com carga total $q$, movendo-se com velocidade escalar constante $c$ e sujeita a uma aceleração centrípeta 
$a_{c}(t)$. No caso de uma onda eletromagnética não há deslocamento de massa, pois a onda eletromagnética não possui massa. Por isso, o fator relativístico que considera o aumento de energia cinética, que é devido à aceleração de um corpo com massa não nula, não precisa ser considerado nessa expressão. De fato, como será mostrado mais adiante, o valor do campo elétrico obtido por simulação é idêntico ao valor do campo elétrico de uma carga puntiforme sem o fator relativístico, confirmando esse fato.

Dado que a aceleração para cada ponto da antena é conhecida, pode-se encontrar a energia perdida e estimar o decaimento da corrente devido à radiação.

Seja a corrente modelada por um pulso retangular de amplitude $i(l)$ e largura $d t=1 / f_{\max }$, sendo $f_{\max }$ a frequência máxima utilizada na simulação. O pulso se propaga pela linha com velocidade $c$ e, portanto, a largura ocupada por ele na linha será $d l=c d t$. Deseja-se acompanhar somente o decaimento em amplitude e não as possíveis distorções presentes. Dado que a redução da corrente devido à perda de energia para radiação seja $d i$, a potência relacionada a essa perda de corrente, considerando impedância constante será

$$
Z_{0}(d i)^{2}
$$

Igualando a redução de energia na antena com a energia radiada obtida anteriormente, tem-se:

$$
Z_{0}(d i)^{2} d t=\frac{q^{2} a_{c}^{2}(t)}{6 \pi \varepsilon_{0} c^{3}} d t
$$

E substituindo-se $q$ pelo valor da carga associado ao pulso de corrente,

$$
I=\frac{q}{d t}=\frac{q c}{d l} \leftrightarrow q=\frac{I d l}{c}
$$

e a aceleração pela expressão 6.40 , obtem-se

$$
\begin{aligned}
& Z_{0}(d i)^{2}=\frac{i^{2} d l^{2}}{6 \pi \varepsilon_{0} c^{5}} \frac{c^{4}}{b^{2}\left(l-h+\sqrt{1+\frac{1}{b^{2}}} \rho_{0}\right)^{2}} \\
& Z_{0}(d i)^{2}=\frac{i^{2} d l^{2}}{6 \pi} \frac{\eta}{b^{2}\left(l-h+\sqrt{1+\frac{1}{b^{2}}} \rho_{0}\right)^{2}}
\end{aligned}
$$

Sendo $\eta=\sqrt{\mu_{0} / \varepsilon_{0}}$ a impedância intrínseca do meio. Rearranjando-se os termos, obtem-se: 


$$
\begin{gathered}
\left(\frac{d i}{d l}\right)^{2}=i^{2} \frac{\eta}{6 \pi Z_{0} b^{2}\left(l-h+\sqrt{1+\frac{1}{b^{2}}} \rho_{0}\right)^{2}} \\
\frac{d i}{d l}= \pm \frac{i}{b\left(l-h+\sqrt{1+\frac{1}{b^{2}}} \rho_{0}\right)} \sqrt{\frac{\eta}{6 \pi Z_{0}}}
\end{gathered}
$$

Expressão que vale apenas para $l>h$. Dessa forma, deve-se apenas tomar o sinal negativo, para ser consistente com uma diminuição da amplitude associada a perda de energia por radiação.

Deseja-se obter o valor do pico do pulso de corrente à medida que ele se propaga na antena, $i(l)$. Supondo uma solução do tipo $i(l)=C e^{\alpha(l)}$, onde $C$ é uma constante determinada pela condição inicial, então, $\frac{d i}{d l}=C e^{\alpha(l)} \alpha^{\prime}(l)$, substituindo em $6.48 \mathrm{e}$ simplificando,obtemos:

$$
\alpha^{\prime}(l)=-\frac{1}{b\left(l-h+\sqrt{1+\frac{1}{b^{2}}} \rho_{0}\right)} \sqrt{\frac{\eta}{6 \pi Z_{0}}}
$$

Integrando para se obter a função de decaimento,

$$
\alpha(l)=-\ln \left(l-h+\sqrt{1+\frac{1}{b^{2}}} \rho_{0}\right) \frac{1}{b} \sqrt{\frac{\eta}{6 \pi Z_{0}}}+K
$$

A solução será então

$$
i(l)=C e^{-\ln \left(l-h+\sqrt{1+\frac{1}{b^{2}}} \rho_{0}\right) \frac{1}{b} \sqrt{\frac{\eta}{6 \pi Z_{0}}}+K}
$$

Adotando-se $i(l=h)=C$

$$
C=C e^{-\ln \left(\sqrt{1+\frac{1}{b^{2}}} \rho_{0}\right) \frac{1}{b} \sqrt{\frac{\eta}{6 \pi Z_{0}}}+K}
$$

E a constante $K$ pode ser determinada como segue

$$
\begin{gathered}
-\ln \left(l-h+\sqrt{1+\frac{1}{b^{2}}} \rho_{0}\right) \frac{1}{b} \sqrt{\frac{\eta}{6 \pi Z_{0}}}+K=0 \\
K=\ln \left(l-h+\sqrt{1+\frac{1}{b^{2}}} \rho_{0}\right) \frac{1}{b} \sqrt{\frac{\eta}{6 \pi Z_{0}}}
\end{gathered}
$$

Portanto,

$$
i(l)=C e^{-\frac{1}{b} \sqrt{\frac{\eta}{6 \pi Z_{0}}} \ln \left(\frac{l-h+\sqrt{1+\frac{1}{b^{2}}} \rho_{0}}{\sqrt{1+\frac{1}{b^{2}}} \rho_{0}}\right)}=C e^{-\frac{1}{b} \sqrt{\frac{\eta}{6 \pi Z_{0}}} \ln \left(\frac{l-h}{\sqrt{1+\frac{1}{b^{2}}} \rho_{0}}+1\right)}
$$


Substituindo-se 6.15

$$
i(l)=C e^{-\frac{1}{b} \sqrt{\frac{\eta}{6 \pi Z_{0}}} \ln \left(\frac{\rho}{\rho_{0}}\right)}=C e^{\ln \left(\left(\frac{\rho}{\rho_{0}}\right)^{-\frac{1}{b} \sqrt{\frac{\eta}{6 \pi Z_{0}}}}\right)}=C\left(\frac{\rho_{0}}{\rho}\right)^{\frac{1}{b} \sqrt{\frac{\eta}{6 \pi Z_{0}}}}
$$

\subsection{Modelo simplificado}

A solução analítica obtida para a corrente na antena espiral pode ser comparada com a corrente simulada para verificar se uma solução desse tipo se adapta ao tipo de decaimento esperado. Para tanto é importante utilizar um ponto longe do início da antena para o cálculo da constante $C$. No começo da antena vários fenômenos estão presentes como a radiação do gerador e reflexões.

Diversos modelos de impedância variável da linha foram testados porém nenhum apresentou resultado satisfatório. Por isso, foi escolhido utilizar o modelo mais simples que é uma impedância constante $Z_{0}$ e igual à impedância do meio $\eta$. A corrente $i(l)$ é a obtida substituindo os valores na expressão 6.51

$$
i(l)=\frac{0.134}{(l+0.023)^{0.542}}
$$

Na Figura 6.4, estão representadas as diferentes posições do pulso deslocando-se ao longo do comprimento da antena $l$ obtidos por simulação com o NEC. A linha contínua representa $i(l)$ 


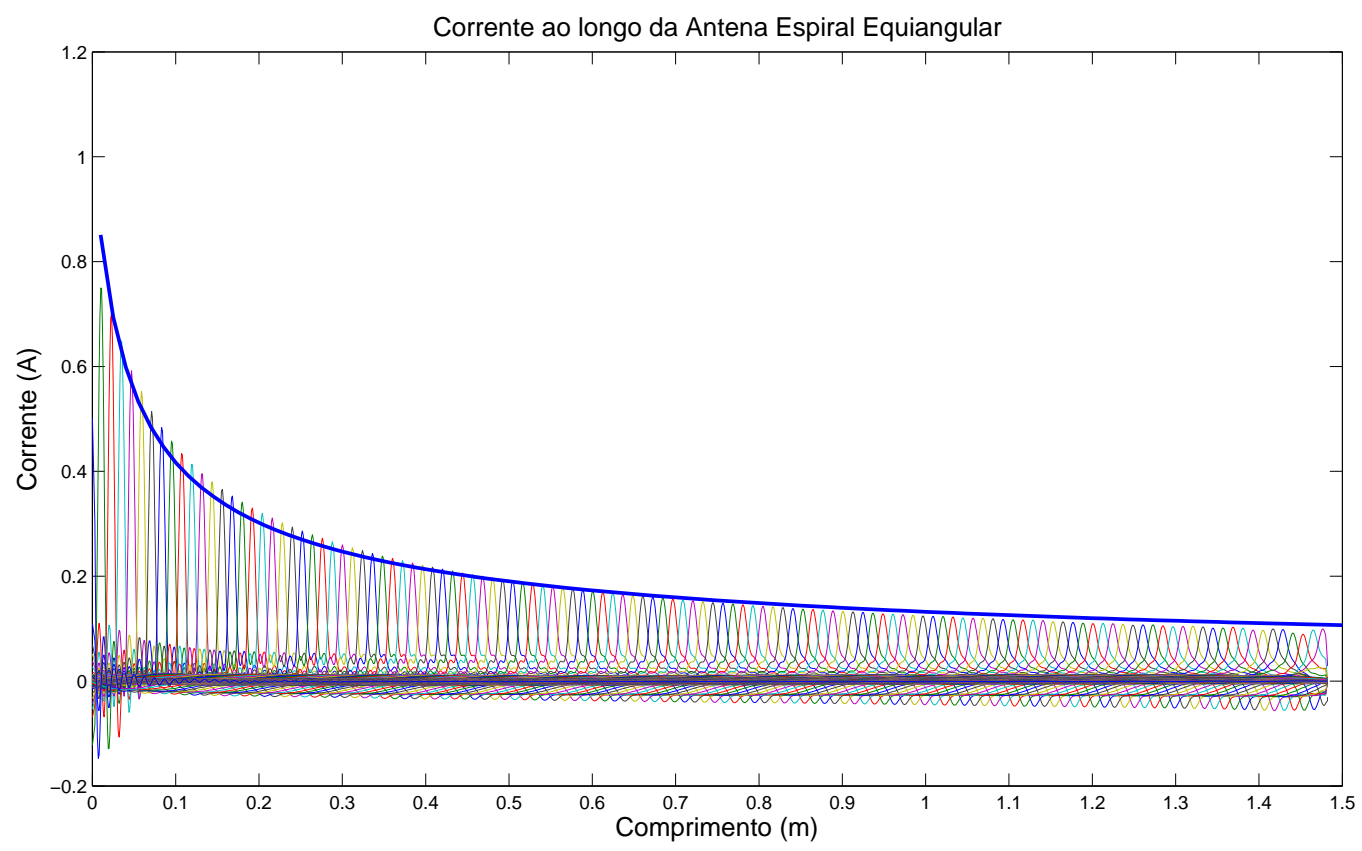

Figura 6.4: Corrente simulada $\mathrm{x}$ analítica

Percebe-se que esse tipo de solução é realmente adequada para representar o decaimento da corrente na antena espiral equiangular, indicando que esse modelo de cálculo para o decaimento do pulso de corrente ao se propagar pela linha é uma ótima aproximação para o fenômeno de troca de energia entre a antena e o espaço, servindo até para regiões próximas a fonte.

\subsection{Estimativa do campo em valor absoluto e com o decaimento da corrente}

Para aproximar analiticamente a resposta impulsiva da antena espiral no domínio do tempo, a antena pode ser modelada por duas cargas elétricas puntiformes e de sinal contrário cujo deslocamento se dá na trajetória correspondente aos dois braços da espiral, sendo que cada carga percorre um dos braços. Será utilizada uma aproximação simplificada considerando somente a radiação que ocorre ao longo do braço da espiral, ou seja, sem levar em conta a radiação causada pela fonte e pela extremidade. As características dos pulsos radiados pela fonte e pela extremidade são aquelas vistas no caso da antena dipolo [38].

O campo radiado por uma carga que se move em uma trajetória qualquer é dado pela soma das equações 6.29 e 6.31 de [36]: 


$$
\begin{gathered}
\vec{E}(\vec{r}, t)=\vec{E}_{v}(\vec{r}, t)+\vec{E}_{a}(\vec{r}, t) \\
\vec{E}_{a}(\vec{r}, t)=\frac{q}{4 \pi \varepsilon_{0} c^{2}}\left\{\frac{\hat{R}_{q} \times\left[\left(\hat{R}_{q}-\overrightarrow{v_{a}} / c\right) \times \vec{a}\right]}{R_{q}\left|1-\hat{R}_{q} \cdot \overrightarrow{v_{a}} / c\right|^{3}}\right\}_{t r} \\
\vec{E}_{v}(\vec{r}, t)=\frac{q}{4 \pi \varepsilon_{0}}\left\{\frac{\left(1-v_{a}{ }^{2} / c^{2}\right)\left(\hat{R}_{q}-\overrightarrow{v_{a}} / c\right)}{R_{q}{ }^{2}\left|1-\hat{R}_{q} \cdot \overrightarrow{v_{a}} / c\right|^{3}}\right\}_{t r}
\end{gathered}
$$

Onde^ representa o versor na direção indicada, $\vec{E}_{v}$ é conhecido como campo de velocidade, $\vec{E}_{a}$ é conhecido como campo de aceleração, $\hat{R}_{q}$ é o vetor unitário na direção que une a carga e o ponto de observação $P, \vec{r}$ é o vetor que liga o origem do sistema de coordenadas à carga, $\overrightarrow{v_{a}}$ é a velocidade da onda de carga, $\vec{a}$ a aceleração da carga e $q$ o seu valor. As equações 6.59 e 6.60 devem ser avaliadas no tempo. A Figura 6.5 ilustra esses vetores.

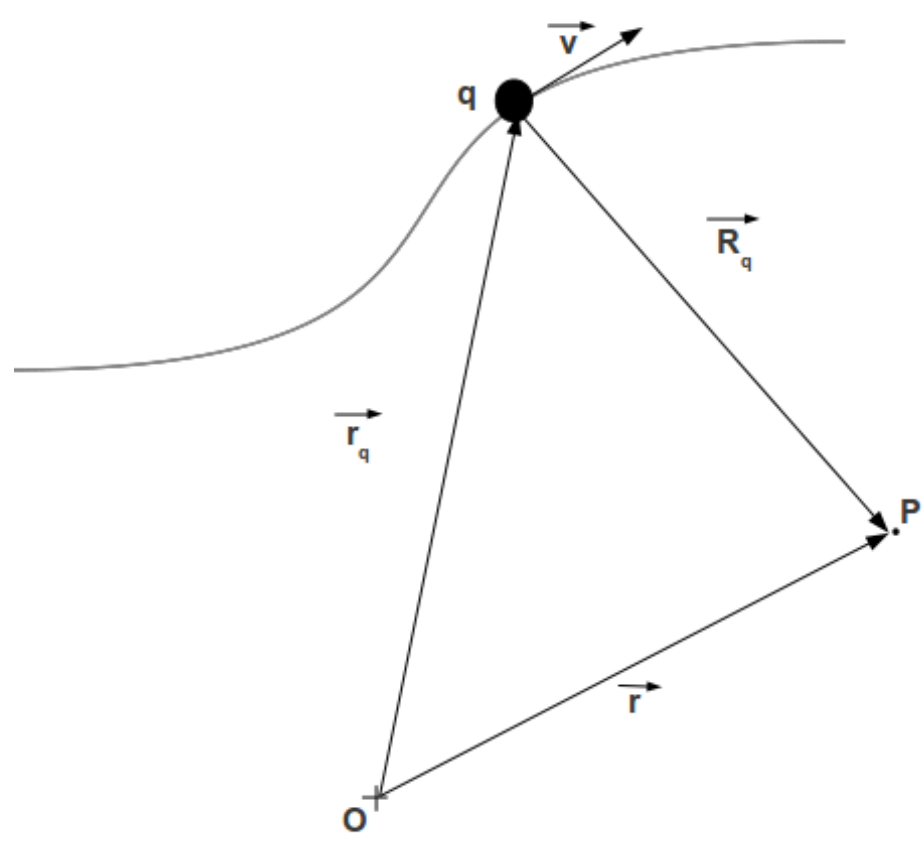

Figura 6.5: Definição dos vetores de posição utilizados na equação 6.59

Pode-se ver, então, que o campo de velocidade varia com $R_{q}{ }^{2}$ e portanto, podendo ser desprezado em uma análise de campo distante e considerar somente o campo de aceleração. Ou seja, a radiação em campo distante é causada somente pela aceleração de cargas. 
O campo radiado devido à aceleração de cargas, é dado por 6.59 , onde a relação entre a carga e a corrente é

$$
I=\lambda v=\frac{q}{d l} v,
$$

Levando em conta que o comprimento percorrido $d l=v d t$, onde $d t$ é a largura do pulso. A largura do pulso é a largura do sinc, $d t=1 / 25 \cdot 10^{9}$, devido à limitação em banda da simulação.

$$
I=\frac{q}{d t} \rightarrow q=I d t
$$

E, portanto, o campo será

$$
\vec{E}_{a}(\vec{r}, t)=\frac{\mu_{0} I d t}{4 \pi}\left\{\frac{\hat{R}_{q} \times\left[\left(\hat{R}_{q}-\overrightarrow{v_{a}} / c\right) \times \vec{a}\right]}{R_{q}\left(1-\hat{R}_{q} \cdot \overrightarrow{v_{a}} / c\right)^{3}}\right\}_{t r}
$$

Para incluir o efeito do decaimento da corrente no campo radiado foi utilizada a expressão analítica obtida nas seções anteriores para a corrente. A Figura abaixo mostra o campo calculado com e sem considerar o decaimento da corrente, comparados com o campo simulado.

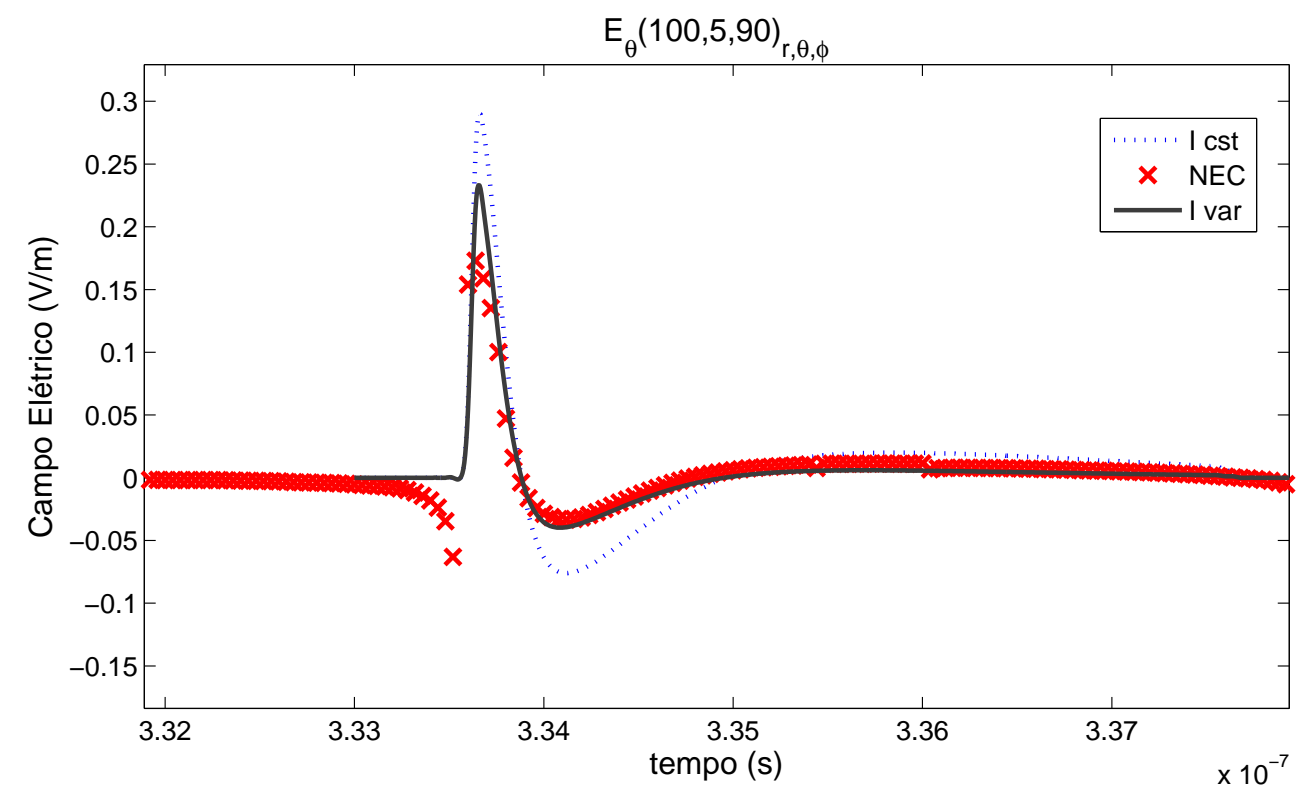

Figura 6.6: Campo distante $E_{\theta}$ observado no ponto $R=100, \theta=5^{\circ}, \phi=90^{\circ}$, campo obtido por simulação $(N E C)$ comparado com o campo considerando corrente constante $\left(I_{c s t}\right)$ e corrente com decaimento $\left(I_{\text {var }}\right)$

A discrepância inicial é devida à radiação do gerador que não foi inclusa no 
modelo de decaimento. Esse gráfico é apenas um exemplo típico do cálculo do campo dessa antena, os valores do campo para outras direções e distâncias também foram analisados e a concordância é satisfatória. 


\section{Capítulo 7}

\section{Conclusão}

A análise de antenas no domínio do tempo acrescenta uma nova visão ao funcionamento das mesmas, já bem conhecidas no domínio da frequência. Neste estudo foram exploradas antenas de dimensões grandes o suficiente para que se pudesse ver claramente o pulso de corrente se propagando na estrutura, de forma a relacionar com esse percurso as características de radiação da antena.

Vale ressaltar que, apesar das antenas analisadas apresentarem dimensões inadequadas para as comunicações, o estudo de antenas com dimensões em torno de um metro e pulsos em torno de 1 ns representa um modelo em escala de uma antena com comprimento em torno de $1 \mathrm{~cm}$ e um pulso de $10 \mathrm{ps}$, ou ainda uma antena de $10 \mathrm{~cm}$ e um pulso de $100 \mathrm{ps}$.

Pelo estudo de antenas no domínio do tempo com essas configurações, foi possível discriminar a origem da radiação em detalhe e relacioná-la diretamente com o tipo de aceleração de cargas que a estrutura da antena promove. Essa informação é importante para se ter um controle maior sobre a resposta no domínio do tempo. De posse do conhecimento da origem da radiação, a antena pode ser projetada para promover mecanismos de radiação capazes de dissipar a energia mais rapidamente, por exemplo, reduzindo a dispersão do sinal transmitido. Um mecanismo que pode ser utilizado é a curvatura do fio.

Curvar a antena é mais interessante do que carregá-la com um perfil resistivo que ocasionaria perda na quantidade de potência radiada.

De fato, para explorar o efeito da curvatura, decidiu-se estudar a antena espiral equiangular devido às suas características de antena de banda larga e curvatura variável.

Nesse trabalho foi mostrado que, a partir das expressões das coordenadas da antena, é possível encontrar a corrente e o campo distante radiado. Tal estudo se mostrou produtivo e interessante pelos seguintes fatores 
- Abordagem física do fenômeno de radiação de antenas relacionando diretamente a aceleração centrípeta com o campo radiado e o decaimento do pulso.

- Proporcionou um método para se encontrar o campo elétrico radiado por qualquer fio curvo.

- Demonstra um novo método para encontrar o decaimento da corrente através de uma equação de balanço energético que poderá ser estendida e validada para outras antenas

- Resultados analíticos e quantitativos muito próximos aos valores do decaimento de corrente e do campo elétrico.

- Dispensa o uso de softwares especiais para a simulação eletromagnética e reduz o tempo de simulação

Portanto, ao analisar a antena espiral equiangular da forma proposta, foi possível resolver o problema da antena no que concerne o decaimento da corrente ao longo do seu comprimento e o seu campo radiado de forma quantitativa. Esse resultado abre portas para o estudo de outras antenas utilizando os mesmos procedimentos descritos nesse trabalho. 


\section{Capítulo 8}

\section{Anexos}

Os anexos seguintes apresentam uma amostra dos programas e arquivos gerados durante esse trabalho. O primeiro arquivo é um arquivo de projeto da antena para garantir que todos os segmentos possuem o mesmo tamanho.

Os segundo e terceiro arquivos são uma amostra dos arquivos de entrada e saída do 4NEC2. O arquivo de entrada possui todos os segmentos criados na planilha de projeto e configurações do tipo de fonte e sua posição, um cartão de rotação da estrutura para produzir o segundo braço da espiral, a especificação das frequências em que a simulação deverá ser realizada e a distância do ponto de observação e os ângulos de interesse. O arquivo de saída lista as correntes em cada segmento para todas as frequências solicitadas no arquivo de entrada, além dos campos para todas as frequências.

Em seguida estão um programa feito em MATLAB para leitura automática e extração dos dados do NEC2 e um arquivo em Mathematica para cálculo e exportação do campo elétrico. 


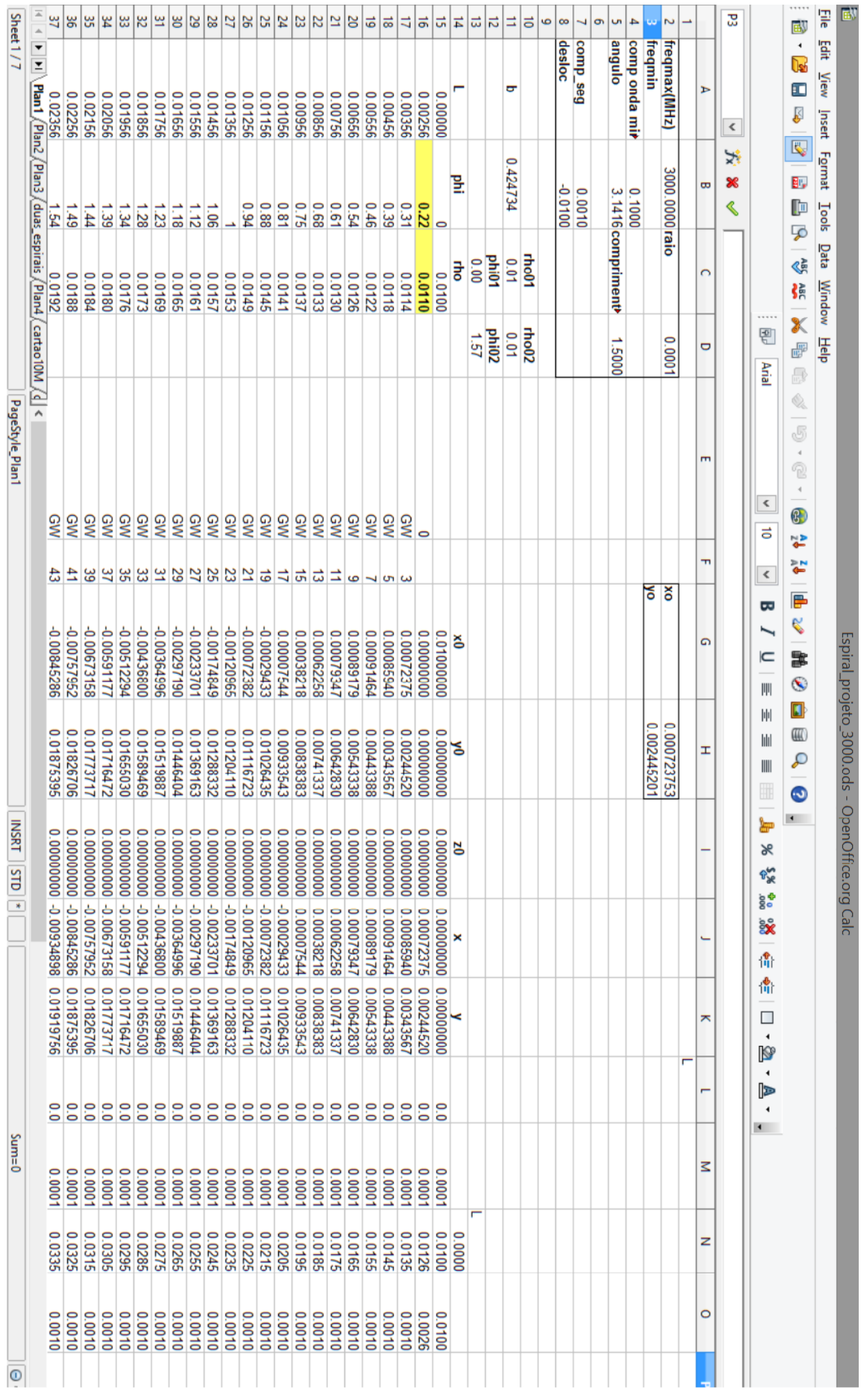

Figura 8.1: Arquivo feito para o projeto da espiral com segmentos de tamanhos iguais 


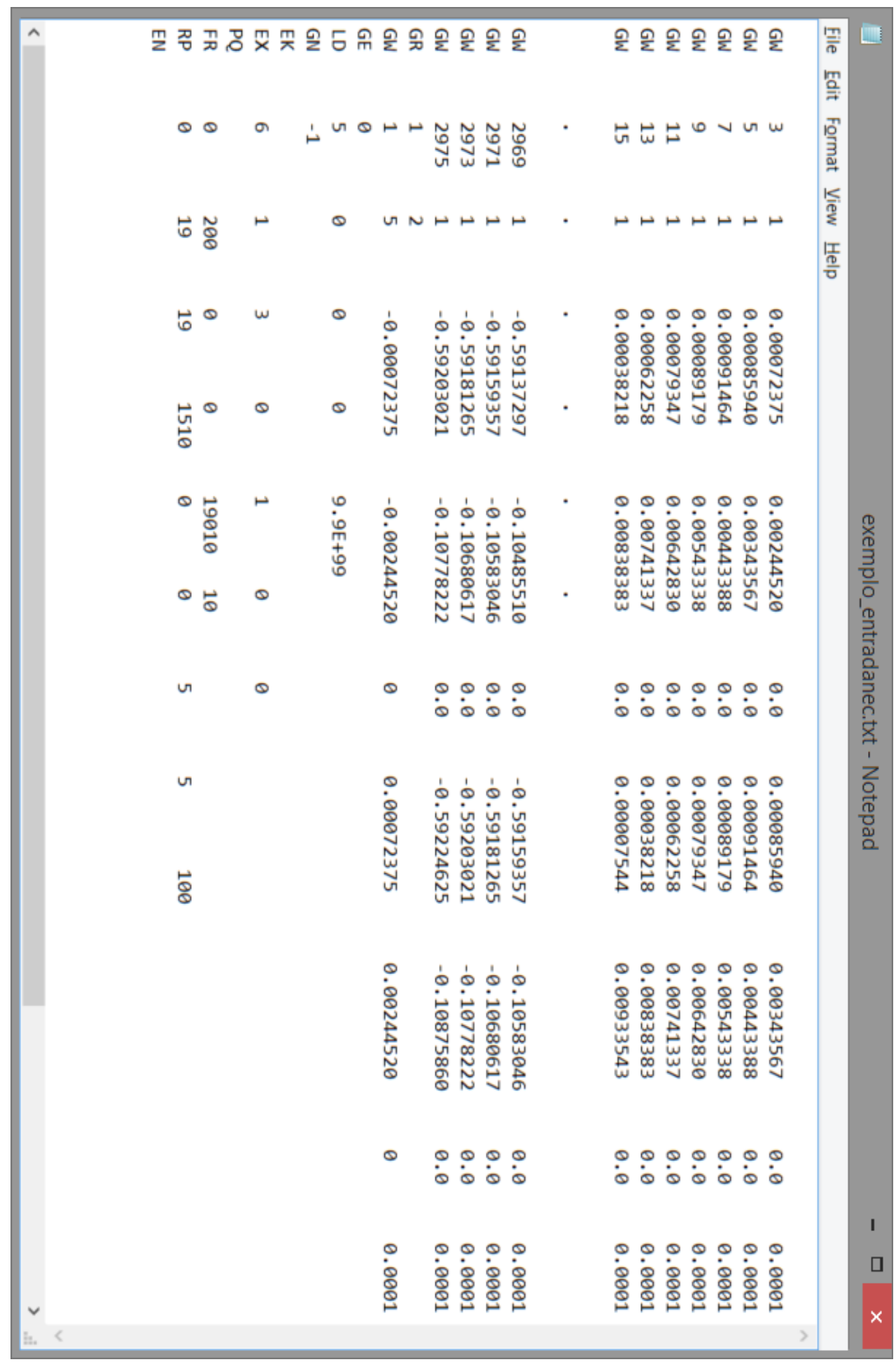

Figura 8.2: Arquivo de entrada do programa NEC com os segmentos da antena espiral, as frequências de simulação, a especificação da fonte e pontos de observação 


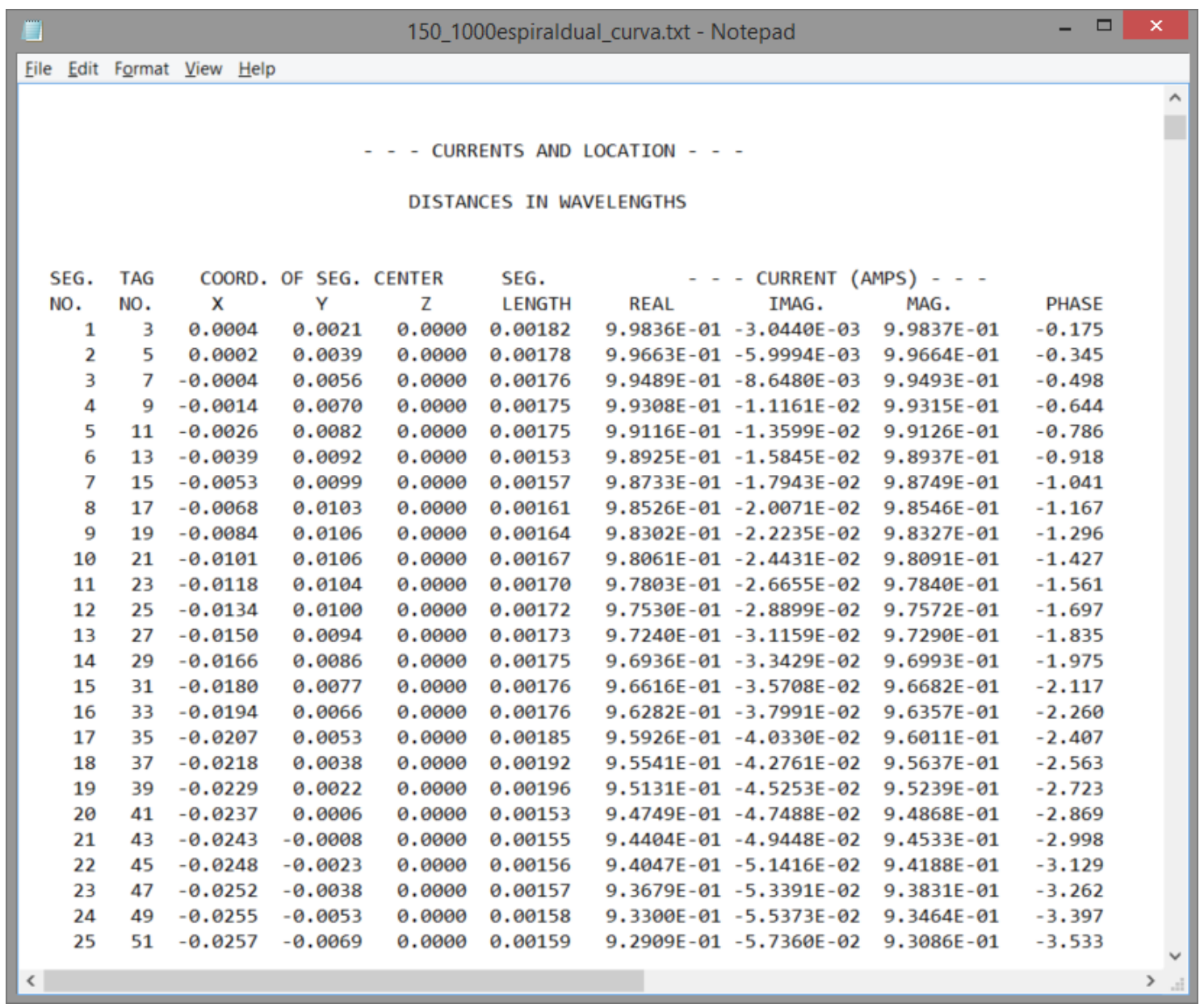

Figura 8.3: Trecho do arquivo de saída do programa NEC com a corrente e sua posição na antena 


\section{$\% \% \% \% \% \% \% \% \% \% \% \% \% \% \% \% \% \% \% \% \% \% \% \% \% \% \% \% \% \% \% \%$ \\ \% Z dado em coordenadas cartesianas \% \\ \% Eteta em coordenadas polares \% \\ \% I dado em coordenadas cartesianas \% \\ $\% \% \% \% \% \% \% \% \% \% \% \% \% \% \% \% \% \% \% \% \% \% \% \% \% \% \% \%$}

$\% \% \% \% \% \% \% \% \% \% \% \% \% \% \% \% \% \% \%$

\% Leitura Arquivo NEC \%

$\% \% \% \% \% \% \% \% \% \% \% \% \% \% \% \% \% \%$

$1=1.85 ; \% \mathrm{em} \mathrm{cm}$

tau $=1 * 10 \wedge-9 ; \%$ segundos

raio $=100 ; \%$ metros

$c=3 * 10 \wedge 8$;

$t=\left[\begin{array}{llll}0 & 140 & 1000: 2000: 25000] ;\end{array}\right.$

$\mathrm{df}=10$;

for $g=1:$ length $(t)-1$;

arquivos = sprintf ('\%d_odespiraldual_curva.txt', $(t(g)+d f),(t(g+1)))$;

\%armazenar informações do cartão RP

nome_arquivo = arquivos;

fid = fopen (nome_arquivo);

RP_Card = findstr(' RP ', fscanf (fid, ['\%C'],500000));

fseek (fid, RP_Card (1)+2, 'bof') ;

RP_string $=$ fscanf $\left(\mathrm{fid},{ }^{\prime} \% \mathrm{C}^{\prime}, 100\right)$;

RP_float $=$ sscanf (RP_string, '\%lf');

fclose ('all')

\%armazenar informações do cartão FR

fid = fopen (nome_arquivo);

FR_Card $=$ findstr('FR ', f $\left.\operatorname{scanf}\left(f i d,\left[{ }^{\circ} \mathrm{C} '\right]\right)\right)$;

fseek (fid, FR_Card (1) +2, ' bof ') ;

FR_string $=f \operatorname{scanf}\left(\mathrm{fid},{ }^{\prime} \% \mathrm{C}^{\prime}, 100\right)$;

FR_float $=$ sscanf (FR_string, $\left.\% l f^{\prime}\right)$;

if FR_float $(6)==0$

FR_float $(6)=1$;

end

varr_freq $=$ FR_float (5) :FR_float (6) : (FR_float (5) +FR_float (6)*(FR_float (2) - 1)); fclose (fid);

fid = fopen (nome_arquivo);

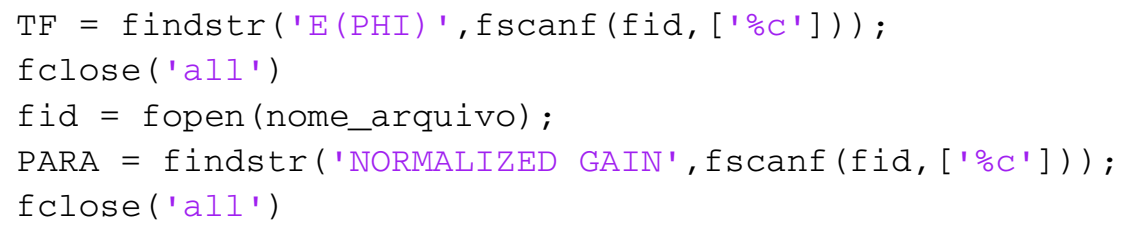


RP_calculated_str $=$ f $\operatorname{scanf}\left(\mathrm{fid}, \mathrm{\prime}^{\circ} \mathrm{C}, \mathrm{PARA}(\mathrm{k})-\mathrm{TF}(\mathrm{k})\right)$;

RP_calculated_flt $(:,:, k)=\operatorname{sscanf}\left(R P \_c a l c u l a t e d \_s t r, ~ \% l f \% l f \% l f \% l f \% l f \% l f \% l f \boldsymbol{l}\right.$

$\%{ }^{*} \%$ lf \%lf \%lf \%lf', [11,RP_float(2)*RP_float(3)]).';

fclose ('all');

end

fid = fopen (nome_arquivo);

LINE = findstr('CURRENTS AND LOCATION', fscanf(fid, ['\%C'])) ;

fclose (fid);

fid = fopen (nome_arquivo);

PAR = findstr ('CHARGE DENSITIES', f scanf $\left.\left(\mathrm{fid},\left[\mathrm{I}^{\circ} \mathrm{C} '\right]\right)\right)$;

for $\mathrm{k}=1:$ length (LINE)

fseek (fid, LINE (k)+272, - 1);

I_calculated_str $=\mathrm{f} \operatorname{scanf}\left(\mathrm{fid}, \mathrm{\prime}^{\circ} \mathrm{C}, \operatorname{PAR}(\mathrm{k})-\operatorname{LINE}(\mathrm{k})\right)$;

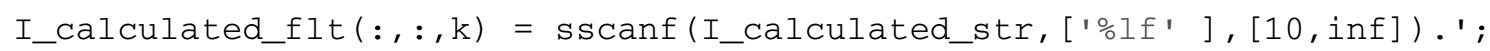
end

clear LINE PAR

fid = fopen (nome_arquivo);

LINE = findstr('SEGMENTATION DATA', fscanf (fid, ['\%c']));

fclose (fid);

fid = fopen (nome_arquivo);

PAR = findstr (' DATA CARD NO. 1 LD', fscanf(fid, ['\% ' $]))$;

f seek (fid, LINE+272+107, - 1)

centro_seg_str $=\mathrm{f}$ scanf $\left(\mathrm{fid}, \mathrm{I}^{\circ} \mathrm{C}, \mathrm{PAR}-(\mathrm{LINE}+1180)\right)$;

centro_seg_flt $=\operatorname{sscanf}\left(\right.$ centro_seg_str, $\left[{ }^{\prime} \% 1 \mathrm{f} '\right],[12$, inf $\left.]\right) . '$;

eval (['centro_seg_' num2str(g) '=centro_seg_flt $(:, 2: 5)$ ']) ;

$\% \% \% \% \% \% \% \% \% \% \% \% \% \% \% \% \% \% \% \% \%$

\% Caso gerador de corrente Ex6 \%

$\% \% \% \% \% \% \% \% \% \% \% \% \% \% \% \% \% \% \% \% \% \% \%$

fclose (fid);

fid = fopen (nome_arquivo);

LINE = findstr('STRUCTURE EXCITATION DATA AT NETWORK CONNECTION POINTS',fscanf(fid, $\left.\left[\left(\% \mathrm{C}^{\prime}\right]\right)\right)$;

fclose (fid);

fid = fopen (nome_arquivo);

PAR = findstr ('ANTENNA INPUT PARAMETERS',fscanf $\left(f i d,\left[\right.\right.$ ' $\left.\left.\left.^{\prime}{ }^{\prime}\right]\right)\right)$;

eval (['I_' num2str(g) '=I_calculated_flt (:, 7:8,:) ']) ;

eval (['Ipos' num2str(g) '=I_calculated_flt $(:, 2,:)$ ']);

eval (['E_' num2str(g) '=RP_calculated_flt $(:, 8: 9,:)$ '] ) ;

eval (['E2_' num2str(g) '=RP_calculated_flt $(:, 10: 11,:)$ '] ) ;

eval (['D_' num2str(g) '=RP_calculated_flt (:,3:5,:) ']);

clear RP_calculated_flt RP_calculated_str RP_string RP_float I_calculated_strk

I_calculated_flt

clearvars - except -regexp E I t df g D LINE PAR

fclose ('all')

end 
ClearAll ["Global`*"]

Needs [ "VectorAnalysis' "]

carga [t_] $:=1$

$\rho\left[t_{-}\right]:=\frac{v b}{\sqrt{b^{2}+1}}(t-\operatorname{delay} / c)+\rho 0$

delay $=\operatorname{Sqrt}\left[0.002445201460612^{\wedge} 2+0.00072375282098^{\wedge} 2\right]$

0.00255006

$\phi\left[t_{-}\right]:=\frac{\log [\rho[t] / \rho 0]}{b}+\phi 0$

$\phi[0] / .\{v \rightarrow v a, b \rightarrow 0.424734, \phi 0 \rightarrow 0.2241845\}$

$0.224185+2.35441 \log \left[\frac{-\frac{0.000996905 \mathrm{va}}{\mathrm{c}}+\rho 0}{\rho 0}\right]$

$\phi[$ delay / c $] /.\{v \rightarrow v a, b \rightarrow 0.424734, \phi 0 \rightarrow 0.2241845\}$

$0.224185+2.35441 \log \left[\frac{\frac{0 . v a}{c}+\rho 0}{\rho 0}\right]$

$\rho[$ delay / c ] /. $\{\mathrm{v} \rightarrow \mathrm{va}, \mathrm{b} \rightarrow 0.424734, \phi 0 \rightarrow 0.22418451576696\}$

$\frac{0 \cdot \mathrm{va}}{\mathrm{c}}+\rho 0$

$x q 1[t]]:=\rho[t] \operatorname{Cos}[\phi[t]]-0.01$

xq1 [delay / c] /. $\{v \rightarrow v a, b \rightarrow 0.424734, \phi 0 \rightarrow 0.22418451576696\}$

$-0.01+\left(\frac{0 . \mathrm{va}}{\mathrm{c}}+\rho 0\right) \operatorname{Cos}\left[0.224185+2.35441 \log \left[\frac{\frac{0 . \mathrm{va}}{\mathrm{c}}+\rho 0}{\rho 0}\right]\right]$

$y q_{1}^{1}\left[t_{-}\right]:=\rho[t] \sin [\phi[t]]$

yq1 [delay / c ] /. $\{\mathrm{v} \rightarrow \mathrm{va}, \mathrm{b} \rightarrow 0.424734, \phi 0 \rightarrow 0.22418451576696\}$

$\left(\frac{0 \cdot \mathrm{va}}{\mathrm{c}}+\rho 0\right) \operatorname{Sin}\left[0.224185+2.35441 \log \left[\frac{\frac{0 . \mathrm{va}}{\mathrm{c}}+\rho 0}{\rho 0}\right]\right]$

$z q 1\left[t_{-}\right]:=t 0$

$r q 1[t]:=\{x q 1[t], y q 1[t], z q 1[t]\}$ 


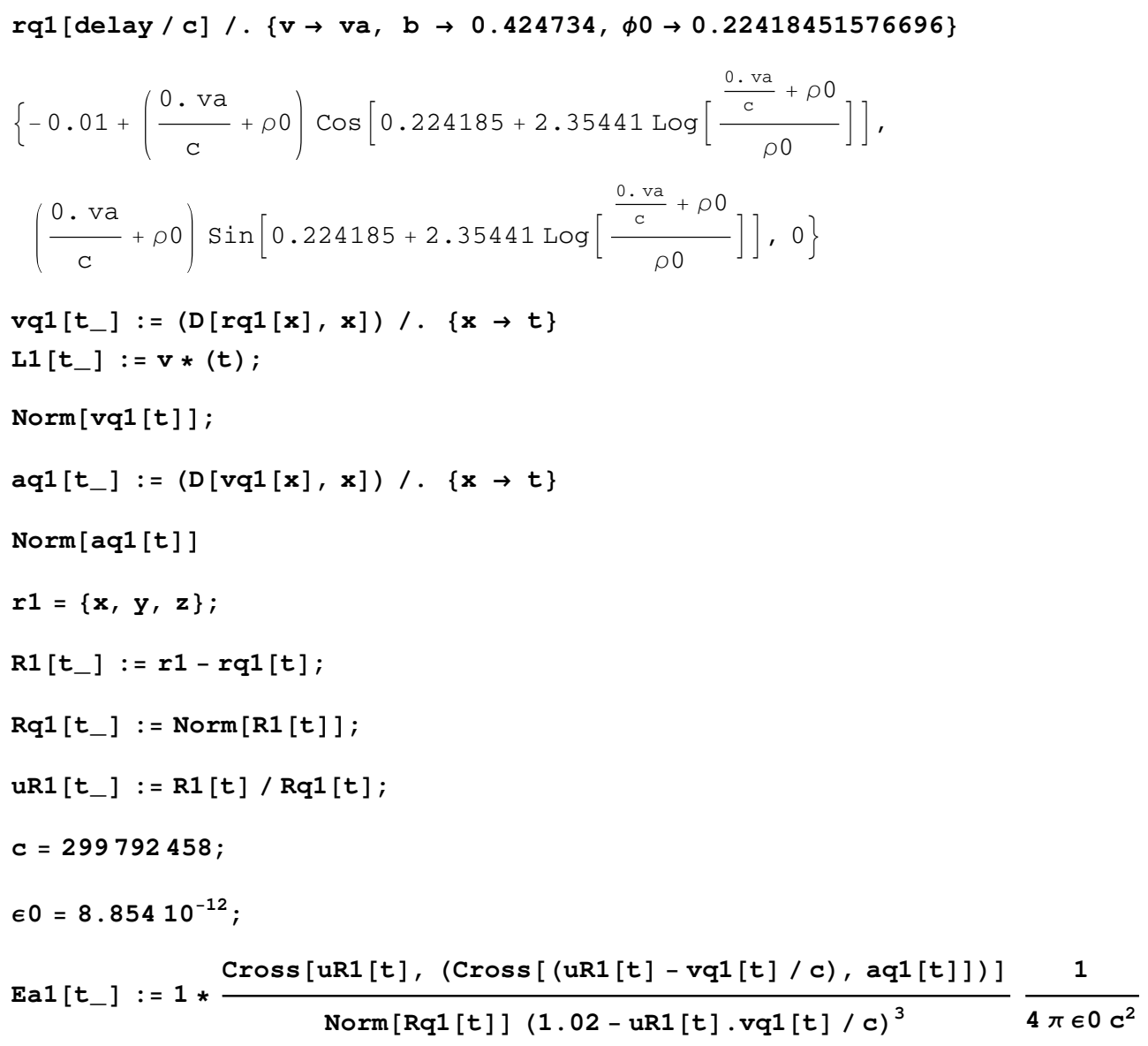




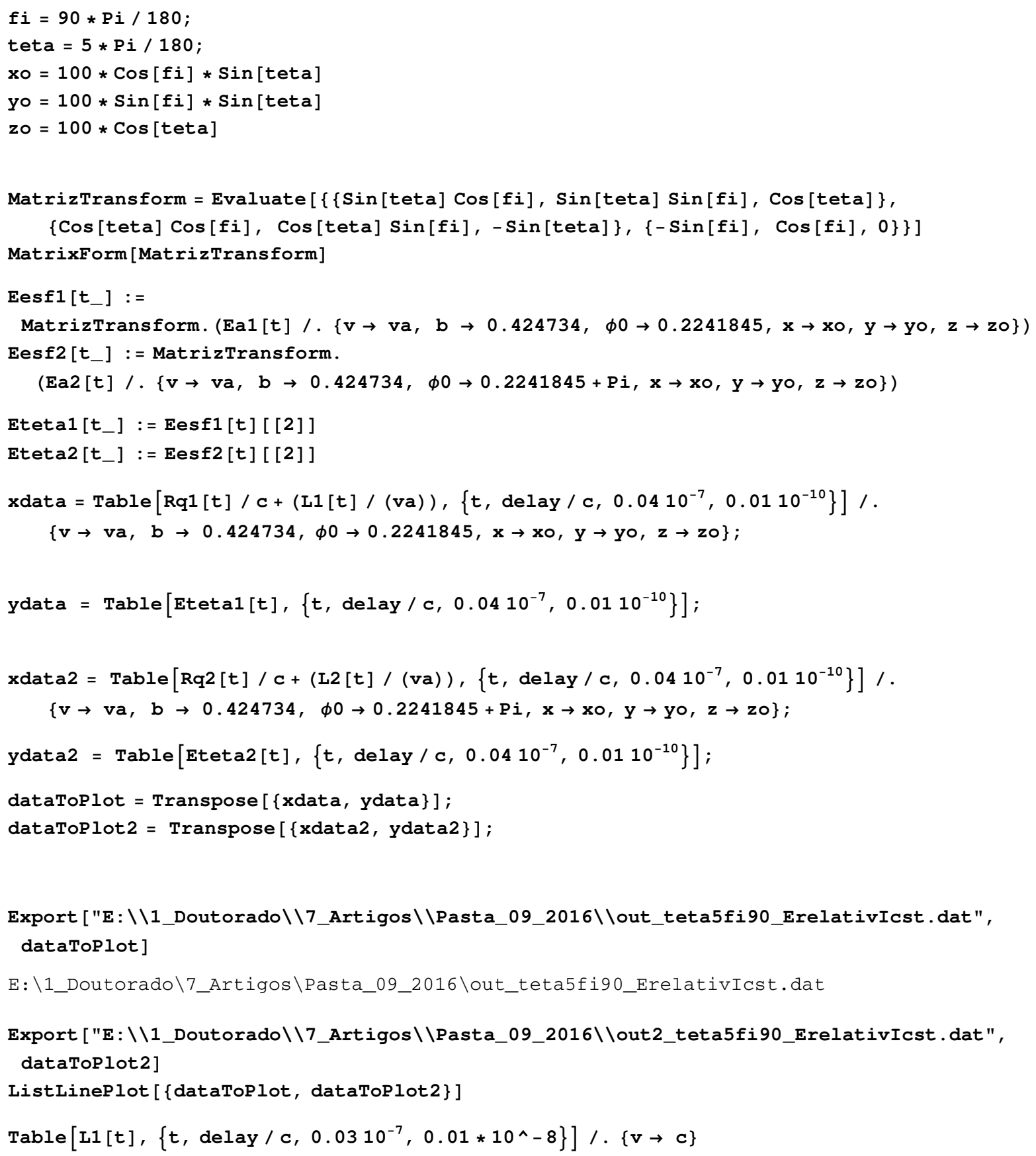




\section{Referências Bibliográficas}

[1] FCC first report and order: In the matter of revision of part 15 of the commission's rules regarding Ultra-Wideband transmission systems, FCC 02-48, april 2002.

[2] Constantine A. Balanis. Antenna Theory: Analysis and Design, 3rd Edition. Wiley-Interscience, 3 edition, April 2005.

[3] F. Bieth, T. Schunck, S. Pinguet, and P. Delmote. Pacemaker Exposure to High-Power Microwave Ultrawideband Radiation. IEEE Transactions on Electromagnetic Compatibility, 56(4):964-969, August 2014.

[4] Jerry Burke and A. Poggio. NEC2 Manual do usuário, 1981.

[5] P. C. Clemmow. An Introduction to Electromagnetic Theory. Cambridge University Press, Cambridge, U.K., 1 edition edition, November 1973.

[6] J. Dyson. The unidirectional equiangular spiral antenna. IRE Transactions on Antennas and Propagation, 7(4):329-334, October 1959.

[7] ECC. Electronic Communications Committee (ECC) Decision, $E C C / D E C /(06) 04$ on the harmonised conditions for using UWB technology in bands below $10.6 \mathrm{GHz}$, July $200 \%$.

[8] Mohamed A. Elmansouri, Saurabh Sanghai, and Dejan S. Filipovic. High-power ultra-wideband spiral antenna arrays. In Radio Science Meeting (USNC-URSI NRSM), 2014 United States National Committee of URSI National, pages 1-1. IEEE, 2014.

[9] R. V. de Freitas and S. E. Barbin. On the impulse response of the folded dipole. In 2013 rth European Conference on Antennas and Propagation (EuCAP), pages 1147-1151, April 2013. 
[10] R. Valerio de Freitas and L. C. Trintinalia. Transient Analysis of the Thin-Wire Equiangular Spiral Antenna. IEEE Transactions on Antennas and Propagation, 62(2):563-568, February 2014.

[11] Renata Valério de Freitas. Análise de antenas no domínio do tempo. São Paulo : Escola Politécnica, Universidade de São Paulo, 2012. Dissertação de Mestrado em Sistemas Eletrônicos.

[12] Alexander T. Gazizov, Alexander M. Zabolotsky, and Olga A. Gazizova. New printed structures for protection against UWB pulses. In 2015 16th International Conference of Young Specialists on Micro/Nanotechnologies and Electron Devices, pages 120-122. IEEE, 2015.

[13] Alexander Talgatovich Gazizov, Alexander Mikhailovich Zabolotsky, and Talgat Rashitovich Gazizov. UWB Pulse Decomposition in Simple Printed Structures. IEEE Transactions on Electromagnetic Compatibility, 58(4):1136-1142, August 2016.

[14] D. Ghosh, A. De, M.C. Taylor, T.K. Sarkar, M.C. Wicks, and E.L. Mokole. Transmission and reception by Ultra-Wideband (UWB) antennas. Antennas and Propagation Magazine, IEEE, 48(5):67-99, 2006.

[15] H.F. Harmuth and Shao Ding-Rong. Antennas for nonsinusoidal waves. i. radiators. Electromagnetic Compatibility, IEEE Transactions on, EMC-25(1):13-24, 1983.

[16] Bradley Curtis Hutchinson. Design of an Ultra-Wideband Spiral Antenna for Ground-Penetrating Microwave Impulse Radar Applications. 2015.

[17] John David Jackson. Classical Electrodynamics Third Edition. Wiley, New York, 3 edition edition, August 1998.

[18] Amir Jafargholi and Manouchehr Kamyab. Pattern optimization in an UWB spiral array antenna. Progress In Electromagnetics Research M, 11:137-151, 2010 .

[19] Oleg D. Jefimenko. Causality Electromagnetic Induction and Gravitation, 2nd ed.: Electret Scientific (Star City - 2000) ISBN 0-917406-23-0.

[20] Jae Sik Kim, Young-Joong Yoon, Hae-Ok Kwon, Jiheon Ryu, and Jin Soo Choi. A Directive Subminiature Antenna for High-Power Ultrawideband Pulse 
Radiation. IEEE Antennas and Wireless Propagation Letters, 13:1565-1568, 2014.

[21] Ioan E. Lager and A. B. Smolders. On the Adequacy of the Far-Field Conditions for Pulsed Radiated EM Fields. IEEE Antennas and Wireless Propagation Letters, 14:1561-1564, 2015.

[22] L. D. Landau. The Classical Theory of Fields. Elsevier, October 2013. Google-Books-ID: HudbAwAAQBAJ.

[23] B. P. Lathi. Modern Digital and Analog Communication Systems. Oxford University Press, New York, 3 edition edition, March 1998.

[24] Jianjun Liu, Karu P. Esselle, Stuart G. Hay, and Shunshi Zhong. Effects of Printed UWB Antenna Miniaturization on Pulse Fidelity and Pattern Stability. IEEE Transactions on Antennas and Propagation, 62(8):3903-3910, August 2014.

[25] Lihua Liu, Xinfan Xia, Shengbo Ye, Jinjin Shao, and Guangyou Fang. Development of a Novel, Compact, Balanced, Micropower Impulse Radar for Nondestructive Applications. IEEE Sensors Journal, 15(2):855-863, February 2015 .

[26] Ifana Mahbub and Syed K. Islam. A low power pulse position modulation based ultra-wideband transmitter for implantable sensors. In Medical Measurements and Applications (MeMeA), 2016 IEEE International Symposium on, pages 1-5. IEEE, 2016.

[27] R.G. Martin, A.R. Bretones, and S.G. Garcia. Some thoughts about transient radiation by straight thin wires. IEEE Antennas and Propagation Magazine, 41(3):24-33, 1999.

[28] R.G. Martin, A. Salinas, and A.R. Bretones. Time-domain integral equation methods for transient analysis. IEEE Antennas and Propagation Magazine, 34(3):15-23, 1992.

[29] Edson Martinod, Michele Lalande, Noel Feix, V. Bertrand, and Rabia Rammal. Measurement of antenna radiation patterns out of anechoic chamber: UWB transient facility in frequency band $[300 \mathrm{MHz}-3 \mathrm{GHz}$. In Antenna Measurements 8 Applications (CAMA), 2014 IEEE Conference on, pages 1-4. IEEE, 2014. 
[30] Adam Maunder and Pedram Mousavi. Application of UWB Arrays for Material Identification of Multilayer Media in Metallic Tanks. IEEE Transactions on Antennas and Propagation, 63(11):4901-4909, November 2015.

[31] E.K. Miller and Jeremy A. Landt. Direct time-domain techniques for transient radiation and scattering from wires. Proceedings of the IEEE, 68(11):1396-1423, 1980.

[32] Sabyasachi Mitra, Sandeep Singh, Senthil Kalyansundaram, Ranjeet Kumar, Archana Sharma, and Kailash Chandra Mittal. Development of $125 \mathrm{kV}, 5$ ns pulse generator for ultra wide band applications. IEEE Transactions on Dielectrics and Electrical Insulation, 22(4):1902-1906, August 2015.

[33] MIC Japanese Ministry of Internal Affairs and Communications. Report summary from UWB radio systems committee information and communications technology Sub-Council, telecommunications council. March 2006.

[34] Abhay K. Rai, Brendan Quine, and Sebastian Magierowski. Design \& development of a compact, low power, high resolution UWB sub-surface scanner for space applications. In 2014 IEEE International Microwave and RF Conference (IMaRC), pages 348-351. IEEE, 2014.

[35] Jurgen Sachs. On the range estimation by UWB-radar. In 2014 IEEE International Conference on Ultra-WideBand (ICUWB), pages 119-124. IEEE, 2014.

[36] Glenn S. Smith. An Introduction to Classical Electromagnetic Radiation. Cambridge University Press, Cambridge, U.K. ; New York, NY, USA, 1 edition edition, August 1997.

[37] F.M. Tanyer-Tigrek, A. Hizal, I.E. Lager, and L.P. Ligthart. On the operating principles of UWB, CPW-Fed printed antennas. Antennas and Propagation Magazine, IEEE, 52(3):46-50, 2010.

[38] Renata Valério de Freitas and Luiz Cezar Trintinalia. Study of the performance of thin-wire dipoles using the time domain impulse response. 2011 SBMO/IEEE MTT-S International Microwave and Optoelectronics Conference.

[39] W. Wiesbeck, G. Adamiuk, and C. Sturm. Basic properties and design principles of UWB antennas. Proceedings of the IEEE, 97(2):372-385, 2009. 
[40] Linda A. Yimdjo Poffelie, Ping Jack Soh, Sen Yan, and Guy A. E. Vandenbosch. A High-Fidelity All-Textile UWB Antenna With Low Back Radiation for Off-Body WBAN Applications. IEEE Transactions on Antennas and Propagation, 64(2):757-760, February 2016. 